\title{
Analytical Investigation on Hybrid Triple Skinned CFST Un- der the Effect of Sudden Impact
}

\author{
Khalid Abdel Naser Abdel Rahim ${ }^{\text {* }}$ \\ ${ }^{1}$ (Khalid Abdel Naser Abdel Rahim): Department of Civil Engineering, University of Coimbra, Coimbra, Portu- \\ gal \\ *Correspondence: khalid.ar@outlook.com;
}

\begin{abstract}
This paper is a continuation of the researches which were carried out by [1-3]. Accordingly this manuscript proposes analytical analysis of a novel triple skin Concrete Filled Steel Tube (CFST) under the effect of sudden impact. Moreover, this is done by extending the double skinned CFST design and installing a third inner CFST inside the second inner tube to achieve the proposed triple skinned CFST design. Furthermore, the propositions consist of two parts. Where the first proposition is a novel triple skin CFST design under the effect of sudden impact, with first sandwich layer filled with Ultra High-Performance Fiber Reinforced Concrete (UHPFRC) and second sandwich layer filled with Normal Strength Concrete (NSC). While the second proposition is a novel triple skin CFST under the effect of sudden impact, with first sandwich layer filled with UHPFRC, second sandwich layer filled with NSC and third skin internal tube filled with NSC. It is strongly believed by the author of this manuscript that (1) the first proposition of novel triple skin CFST will increase the impact resistivity of the structural member by 25 to $32 \%$ and (2) it is predicted that the second proposition of novel triple skin CFST will boost the efficiency of the structural member under the even of sudden impact by 28 to $36 \%$.
\end{abstract}

Keywords: Analytical investigation; Hybrid; Triple Skin; CFST; Sudden Impact

How to cite this paper: Naser $\mathrm{Ab}$ del Rahim, K. A. (2022). Analytical Investigation on Hybrid Triple Skinned CFST Under the Effect of Sudden Impact. World Journal of Civil Engineering and Architecture, 1(1), 2-

33. Retrieved from

https://www.scipublica-

tions.com/journal/in-

dex.php/wjcea/article/view/223

Received: November 20, 2021

Accepted: February 12, 2022

Published: February 15, 2022

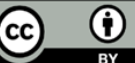

Copyright: (c) 2022 by the authors. Submitted for possible open access publication under the terms and conditions of the Creative Commons Attribution (CC BY) license (http://creativecommons.org/licenses /by/4.0/).

\section{Introduction}

The first part of this paper discusses the Geometrical properties, material properties, cross sectional dimensions, boundary conditions and impact loading conditions of CFDST and CFTST columns. While, the second part debates the Numerical analysis and testing procedure of the models subjected to transverse impact loading. Moreover, the third part of this manuscript demonstrates an overview of the proposed modifications by [1-3]. This is including (1) Concrete Filled Double skin Steel Tubular members under transverse impact load investigation carried out by [19], (2) First Proposed modification by [1-3] CFDST with internal carbon steel tube filled with NSC, (3) Second proposed modification by [1-3] - CFDST with 1st sandwich layer filled with UHPFRC and (4) Third proposed modification by [1-3] - CFDST with 1st sandwich layer filled with UHPFRC and internal carbon steel tube filled with NSC. Furthermore, the fourth part of this paper will deliberate the author propositions of novel triple skin CFST under the effect of sudden impact. Such as, (a) the first proposition of novel triple skin CFST under the effect of sudden impact - CFTST with 1st sandwich layer filled with UHPFRC and 2nd sandwich layer filled with NSC and (b) the second proposition of novel triple skin CFST under the effect of sudden impact - CFTST with 1st sandwich layer filled with UHPFRC, 2nd sandwich layer filled with NSC and 3rd skin internal tube filled with NSC. Finally, but never the least, the conclusion and recommendations for future work will be given based on the novel propositions of triple skin CFST under the effect of sudden impact. 
2. Geometrical properties, material properties, cross sectional dimensions, boundary conditions and impact loading conditions of CFDST and CFTST columns

The geometry of all the numerical models will be circular in accordance to the ones used by [19]. Moreover, the cross-sectional dimensions for all the simulated numerical models has been presented in Tables 1, 2, 3, 4, 5, 6 and 7. Furthermore, there should be a total of six materials which will be used in all the proposed models. These are two types of steel (stainless steel and carbon steel), two types of concrete filling (Normal Strength Concrete (NSC) and Ultra High-Performance Fiber Reinforced Concrete (UHPFRC)) and Glass Fiber Reinforced Polymer (GFRP) with the bonding adhesive. Besides, the material properties of steel by [19] has been presented in Table 1. In addition, Table 2 shows the material properties of concrete used by [15-16] and [19]. Also, the material properties of GFRP and bonding adhesive by [4] has been illustrated in Table 3. Moreover, fixed to fixed boundary conditions at both ends should be used in all the proposed numerical models in accordance to the boundary condition used by [19]. Furthermore, the impact loading conditions for all the simulations of the proposed numerical models has been illustrated in Tables 4, 5, 6, 7, 8 and 9.

Table 1. Material properties of steel by [19].

\begin{tabular}{|c|c|c|c|c|c|}
\hline Steel type & $\mathbf{T}_{\mathbf{s}}(\mathbf{m m})$ & $\begin{array}{c}\mathbf{f}_{\mathbf{y}} \\
\mathbf{M P a})\end{array}$ & $\begin{array}{c}\mathbf{f}_{\mathbf{u}} \\
\mathbf{( M P a})\end{array}$ & $\mathbf{E}_{\mathbf{s}} \mathbf{( M P a )}$ & $\delta$ \\
\hline Stainless steel & 1.88 & 322.1 & 702.5 & $1.91 \times 10^{5}$ & 0.464 \\
\hline \multirow{2}{*}{ Carbon Steel } & 2.01 & 274.6 & 350.5 & $2.08 \times 10^{5}$ & 0.218 \\
\cline { 2 - 7 } & 2.52 & 276.3 & 384.3 & $2.05 \times 10^{5}$ & 0.252 \\
\hline
\end{tabular}

Table 2. Material properties of concrete by [19] and [15-16].

\begin{tabular}{|c|c|c|c|c|}
\hline Researcher & Concrete Type & $\begin{array}{c}\mathbf{f}_{\text {cu,28d }} \\
(\mathbf{M P a})\end{array}$ & $\begin{array}{c}\mathbf{f}_{\text {cu,test }} \\
(\mathbf{M P a})\end{array}$ & $\begin{array}{c}\mathbf{E}_{\mathrm{c}, \text { test }} \\
\mathbf{( M P a})\end{array}$ \\
\hline $\begin{array}{c}\text { Zhao et al. } \\
(2019)\end{array}$ & $\begin{array}{c}\text { Normal Srength } \\
\text { Concrete (NSC) }\end{array}$ & 55.3 & 60.2 & $3.1 \times 104$ \\
\hline $\begin{array}{c}\text { Wang et al. } \\
(2019)\end{array}$ & UHPFRC & 152 & - & - \\
\hline
\end{tabular}

Table 3. Material properties of GFRP and bonding adhesive by [4].

\begin{tabular}{|c|c|c|c|}
\hline $\begin{array}{c}\text { FRP } \\
\text { Type }\end{array}$ & $\begin{array}{c}\text { Elastic Modulus } \\
\text { (GPa) }\end{array}$ & $\begin{array}{c}\text { Tensile Strength } \\
\text { (MPa) }\end{array}$ & $\begin{array}{c}\text { Thickness of FRP } \\
\text { (mm) }\end{array}$ \\
\hline GFRP & 23 & 508 & 0.49 \\
\hline Adhesive & 3 & 46 & Assumed 0.16 \\
\hline
\end{tabular}

The numerical analysis consists from six stages. These are the main design by [19], three design proposals by [1-3] and two design propositions of novel triple skin CFST. Furthermore, each stage involves eighteen numerical simulations. Moreover, all the numerical models will be built and analyses using Abaqus Finite Element Analysis (FEA) software package in accordance to the below user manuals:

- ABAQUS/Explicit User's Manual (version 6.5.1) by Karlsson Sorensen Inc. (2005) [10]. 
- ABAQUS Standard User's Manual (version 6.7) by Dassault Systèmes Corp (2007) [6].

- ABAQUS Standard User's manual (version 6.10) by Hibbitt, Karlsson and Sorensen Inc. (2010) [8].

\section{Numerical analysis and testing procedure of the models subjected to transverse im- pact loading}

All the proposed numerical models should be built and analyzed using Abaqus Finite Element Analysis software package as recommended by [19]. Moreover, all the experimental testing features which were performed by [19] should be taken into consideration in the numerical analysis models. This is including the connection between the concrete filling and the stainless steel and carbon steel tubes. Also, the proposed models should be subjected to the same magnitudes of the combined static axial and dynamic impact loads as per the tested specimens by [19]. Furthermore, the following Stress-Strain models were reformed in accordance to the [19]:

- 2 Stage Stress-Strain model for stainless steel.

- 5 Stage Stress-Strain model for carbon steel.

Again with reference to [19] the rate of strain of the dependent model for the yield strength of stainless steel was not defined. However, the below Cowper-Symonds model equation 1 could be used to calculate the strain-rate dependencies of yield strength for stainless and carbon steels:

$$
\frac{\mathrm{f}_{\mathrm{y}}^{\mathrm{d}}}{f_{y}}=1+\left(\frac{\dot{\epsilon}}{D}\right)^{1 / p},
$$

Where $\mathrm{f}_{\mathrm{y}}^{\mathrm{d}}$ is the dynamic yield stress at strain rate $\dot{\epsilon}, f_{y}$ represents the static yield stress, $\mathrm{D}$ is a factor and was chosen to have a value of $6844 \mathrm{~s}-1$, while $p$ is another factor with a value of 3.91 in accordance to the factors values used by [14]. In order to numerically simulate the behavior of concrete fill under impact loading, the "concrete damaged plasticity model" tool should use with compressive crushing and tensile cracking mechanisms in accordance to [5], [9], [12], [13], [14], [17] and [19]. Furthermore, the confinement of the concrete fill sandwich layer and the concrete core should be defined as "compressive stress-strain model". Besides, the concrete fill in tension should be modeled using "linear stress-strain model" in accordance to the investigation carried out by [11]. Moreover, the main models' parameters such as (1) the ratio of the compressive strength in the biaxial state to uniaxial compressive strength, (2) viscosity, (3) eccentricity, (4) K-parameter and (5) dilation angle should be adjusted at magnitudes of 1.16, 0, 0.1, 0.667 and $30^{\circ}$ respectively. On the other hand, the tensile damage variable $(\mathrm{dt})$ and the compressive damage variable (dc) should not be assigned in the analysis.

The numerical analysis for all the proposed models should go through the below defined stages:

- "Elastic spring model" was used which represents the static axial load on the models.

- The dynamic transverse load should be initiated by positioning the drop hammer near to the numerical sample models. Also, the initial velocity for each simulation should be set depending on the drop height.

- All the analyzed models should be subjected to the gravity acceleration (g) command. 
- "Hard contact friction model" should be assigned in the normal direction and "Coulomb friction model" should be assigned in the tangential direction in order to have a realistic interaction response between the steel tubes and the concrete sandwich layers.

- The friction coefficient for stainless steel tube and concrete interface should be assigned at 0.25 . While, the friction coefficient for carbon steel tube and concrete interface should be assigned at 0.6 with reference to the studies conducted by [7] and [18].

\section{Overview of the proposed modifications by Abdel Rahim (2021)}

This section of this paper will review (1) Concrete Filled Double skin Steel Tubular members under transverse impact load investigation carried out by [19], (2) First Proposed modification by [1-3] - CFDST with internal carbon steel tube filled with NSC, (3) Second proposed modification by [1-3] - CFDST with 1st sandwich layer filled with UHPFRC and (4) Third proposed modification by [1-3] - CFDST with 1st sandwich layer filled with UHPFRC and internal carbon steel tube filled with NSC.

\subsection{Concrete Filled Double skin Steel Tubular members under transverse impact load investigation carried out by Zhao et al. (2019)}

[1-3] has conducted the first stage of the numerical analysis by modelling and evaluating the CFDST specimens which were carried out by [19]. Moreover, the results obtained by [1-3] were compared with the experimental results achieved by [19] for validation purposes and to develop the first proposed design. As shown in Table 4, eighteen numerical models (simulation numbers 1 to 18) has been evaluated by [1-3] without any modifications on the tested specimens by [19]. Furthermore, three main variables were evaluated (hollowness ratio, magnitude of axial load and drop height). In addition, Table 4 presents a detailed list of geometrical properties, cross sectional dimensions and impact loading conditions for CFDST specimens by [19]. Besides, the list which presented in Table 4 includes details of the simulation numbers, specimens tag numbers, type of modification for this stage, diameter and thickness of the steel tubes, length of the specimens, magnitude of axial load, drop heights, impact mass, impact energy and geometry and size of indenter. 
Table 4. List of geometrical properties, cross sectional dimensions and impact loading conditions for CFDST specimens by [19].

\begin{tabular}{|c|c|c|c|c|c|c|c|c|c|c|c|c|c|}
\hline \multirow{2}{*}{ 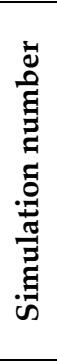 } & \multirow{2}{*}{$\begin{array}{c}\text { Speci- } \\
\text { men } \\
\text { Tag } \\
\text { number }\end{array}$} & \multicolumn{2}{|c|}{$\begin{array}{l}\text { Outer } \\
\text { 1st layer } \\
\text { Stainless } \\
\text { Steel tube }\end{array}$} & \multicolumn{2}{|c|}{$\begin{array}{c}\text { Inner } \\
\text { 2nd layer } \\
\text { Carbon } \\
\text { Steel tube }\end{array}$} & \multicolumn{2}{|c|}{$\begin{array}{l}\text { Inner } \\
\text { 3rd layer } \\
\text { Carbon } \\
\text { Steel tube }\end{array}$} & \multirow{2}{*}{ 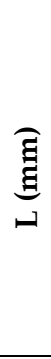 } & \multirow{2}{*}{ 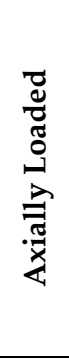 } & \multirow{2}{*}{ 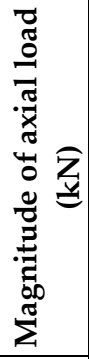 } & \multirow{2}{*}{$\begin{array}{l}\widehat{\Xi} \\
\text { I }\end{array}$} & \multirow{2}{*}{ 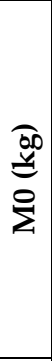 } & \multirow{2}{*}{ 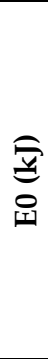 } \\
\hline & & 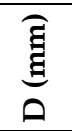 & 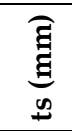 & $\underset{\mathfrak{\Xi}}{\mathfrak{\Xi}}$ & $\begin{array}{l}\underset{\Xi}{\mathfrak{g}} \\
\underset{\infty}{\infty}\end{array}$ & 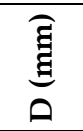 & $\underset{\infty}{\stackrel{\Xi}{\Xi}}$ & & & & & & \\
\hline 1 & L-3-0-a & 114 & 1.88 & 48 & 2.52 & N/A & $\mathrm{N} / \mathrm{A}$ & \multirow{18}{*}{$\underset{\infty}{\stackrel{\infty}{-}}$} & No & 0 & 3 & \multirow{18}{*}{$\stackrel{\widetilde{N}}{\tilde{\sigma}}$} & 6 \\
\hline 2 & L-3-0-b & 114 & 1.88 & 48 & 2.52 & N/A & $\mathrm{N} / \mathrm{A}$ & & No & 0 & 3 & & 6 \\
\hline 3 & L-5-0.5-a & 114 & 1.88 & 48 & 2.52 & N/A & N/A & & Yes & 343 & 5 & & 10 \\
\hline 4 & L-5-0.5-b & 114 & 1.88 & 48 & 2.52 & N/A & N/A & & Yes & 343 & 5 & & 10 \\
\hline 5 & L-7-0.3-a & 114 & 1.88 & 48 & 2.52 & N/A & N/A & & Yes & 206 & 7 & & 14 \\
\hline 6 & L-7-0.3-b & 114 & 1.88 & 48 & 2.52 & N/A & N/A & & Yes & 206 & 7 & & 14 \\
\hline 7 & M-3-0.5-a & 114 & 1.88 & 76 & 2.01 & N/A & N/A & & Yes & 317 & 3 & & 6 \\
\hline 8 & M-3-0.5-b & 114 & 1.88 & 76 & 2.01 & N/A & N/A & & Yes & 317 & 3 & & 6 \\
\hline 9 & M-5-0.3-a & 114 & 1.88 & 76 & 2.01 & N/A & N/A & & Yes & 190 & 5 & & 10 \\
\hline 10 & M-5-0.3-b & 114 & 1.88 & 76 & 2.01 & N/A & N/A & & Yes & 190 & 5 & & 10 \\
\hline 11 & M-7-0-a & 114 & 1.88 & 76 & 2.01 & N/A & N/A & & No & 0 & 7 & & 14 \\
\hline 12 & M-7-0-b & 114 & 1.88 & 76 & 2.01 & N/A & N/A & & No & 0 & 7 & & 14 \\
\hline 13 & H-3-0.3-a & 114 & 1.88 & 89 & 2.01 & N/A & N/A & & Yes & 142 & 3 & & 6 \\
\hline 14 & H-3-0.3-b & 114 & 1.88 & 89 & 2.01 & N/A & N/A & & Yes & 142 & 3 & & 6 \\
\hline 15 & H-5-0-a & 114 & 1.88 & 89 & 2.01 & N/A & N/A & & No & 0 & 5 & & 10 \\
\hline 16 & H-5-0-b & 114 & 1.88 & 89 & 2.01 & N/A & N/A & & No & 0 & 5 & & 10 \\
\hline 17 & H-7-0.5-a & 114 & 1.88 & 89 & 2.01 & N/A & N/A & & Yes & 237 & 7 & & 14 \\
\hline 18 & $\mathrm{H}-7-0.5-\mathrm{b}$ & 114 & 1.88 & 89 & 2.01 & N/A & N/A & & Yes & 237 & 7 & & 14 \\
\hline
\end{tabular}

No Modification - Modelling the same models as [19] and analyzing them for comparing the results. Impactor/Indenter geometry and size - drop hammer with $30 \mathrm{~mm} \times 80 \mathrm{~mm}$ rectangular bottom surface.

A schematic drawing has been shown in Figure 1 of the CFDST cross section and material properties for specimens with hollowness ratio of 0.44 by [19]. As can be seen in Figure 1, the model consists of two steel tubes. The 1st layer outer steel tube is made from stainless steel with an outer diameter of $114 \mathrm{~mm}$ with a tube thickness of $1.88 \mathrm{~mm}$. On the other hand, the second inner steel tube is made from carbon steel and an outer diameter of $48 \mathrm{~mm}$ and a thickness of $2.52 \mathrm{~mm}$. Furthermore, there will be one Normal Strength Concrete (NSC) fill sandwich layer with a compressive strength of 55.3MPa between the outer and the inner steel tubes. On the contrary, the inner carbon steel tube will be hollow/unfilled. Moreover, all the specimens had a standard length of $1800 \mathrm{~mm}$.

This design in figure 1 by [19] will represent simulation numbers 1 to 6 with variations in magnitude of axial load, drop height and impact energy. For example, simulations number 1 and 2 has not been axially load, the drop height has been set at $3 \mathrm{~m}$ and the impact energy will be $6 \mathrm{~kJ}$. While numbers 3 and 4 has been axially loaded with a magnitude of $343 \mathrm{kN}$, the drop height has been set at $5 \mathrm{~m}$ and the impact energy will be around $10 \mathrm{~kJ}$. Furthermore, simulation numbers 5 and 6 has been axially loaded with a magnitude of $206 \mathrm{kN}$, the drop height has been set at $7 \mathrm{~m}$ and the impact energy will be $14 \mathrm{~kJ}$. Moreover, 
the drop mass will have the same magnitude for all the simulations with a value of $203.7 \mathrm{Kg}$. Finally, the geometry of the bottom surface of the drop hammer indenter is rectangular and with a parameter of $30 \mathrm{~mm}$ by $80 \mathrm{~mm}$.

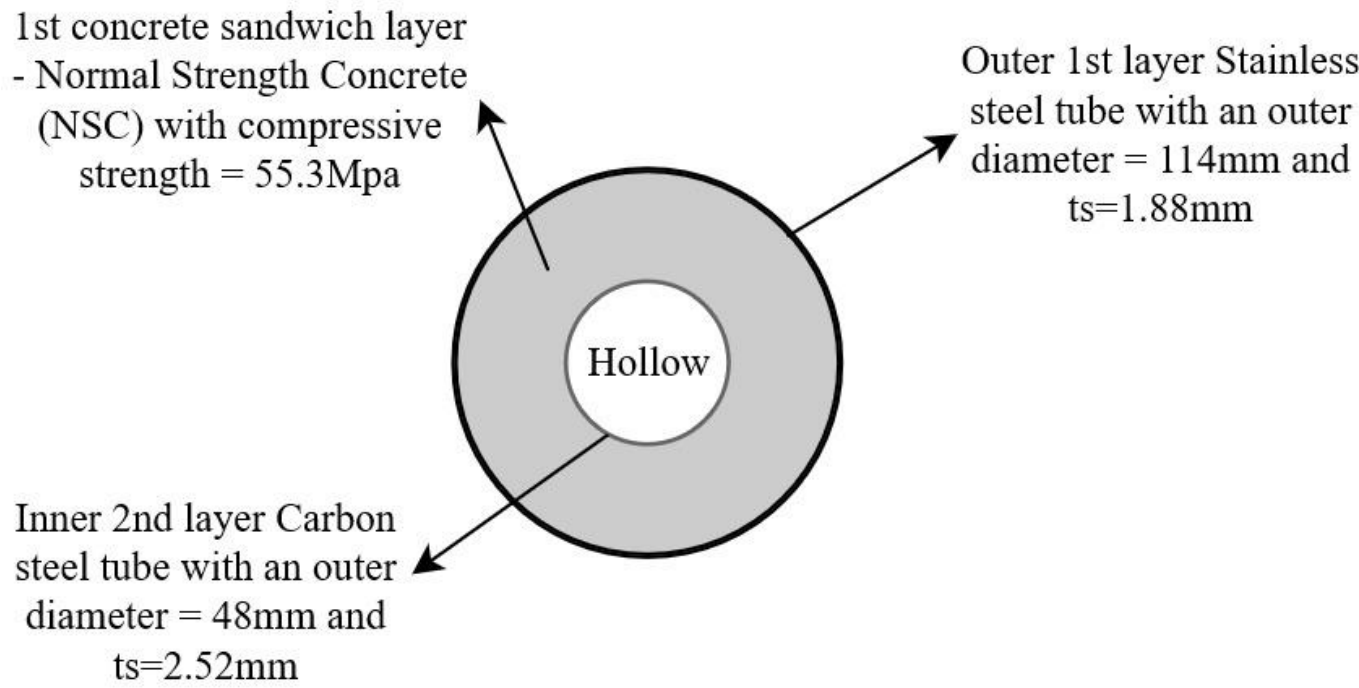

Figure 1. Schematic sketch of the CFDST cross section and material properties for specimens with hollowness ratio of 0.44 by [19].

A schematic drawing has been shown in Figure 2 of the CFDST cross section and material properties for specimens with hollowness ratio of 0.69 by [19]. As can be seen in Figure 2, the model consisted of two steel tubes. The 1st layer outer steel tube is made from stainless steel with an outer diameter of $114 \mathrm{~mm}$ with a tube thickness of $1.88 \mathrm{~mm}$. On the other hand, the second inner steel tube is made from carbon steel and an outer diameter of $76 \mathrm{~mm}$ and a thickness of $2.01 \mathrm{~mm}$. Furthermore, there will be one Normal Strength Concrete (NSC) fill sandwich layer with a compressive strength of 55.3MPa between the outer and the inner steel tubes. On the contrary, the inner carbon steel tube will be hollow/unfilled. Moreover, all the specimens had a standard length of $1800 \mathrm{~mm}$.

This design in figure 2 by [19] represented simulation numbers 7 to 12 with variations in magnitude of axial load, drop height and impact energy. For example, simulations number 7 and 8 has been axially load with a magnitude of $317 \mathrm{kN}$, the drop height has been set at $3 \mathrm{~m}$ and the impact energy will be $6 \mathrm{~kJ}$. While simulation numbers 9 and 10 has been axially loaded with a magnitude of $190 \mathrm{kN}$, the drop height has been set at $5 \mathrm{~m}$ and the impact energy will be around 10kJ. Furthermore, simulation numbers 11 and 12 were not axially loaded, the drop height has been set at $7 \mathrm{~m}$ and the impact energy will be $14 \mathrm{~kJ}$. Moreover, the drop mass had the same magnitude for all the simulations with a value of $203.7 \mathrm{Kg}$. Finally, the geometry of the bottom surface of the drop hammer indenter is rectangular and with a parameter of $30 \mathrm{~mm}$ by $80 \mathrm{~mm}$. 
1st concrete sandwich layer

- Normal Strength Concrete

(NSC) with compressive

\section{(}

$\pi^{\mathrm{s}}$

Outer 1st layer Stainless steel tube with an outer strength $=55.3 \mathrm{Mpa}$
Inner 2nd layer Carbon steel tube with an outer diameter $=76 \mathrm{~mm}$ and ts $=2.01 \mathrm{~mm}$

Figure 2. Schematic sketch of the CFDST cross section and material properties for specimens with hollowness ratio of 0.69 by [19].

A schematic drawing has been shown in Figure 3 of the CFDST cross section and material properties for specimens with hollowness ratio of 0.81 by [19]. As can be seen in Figure 3, the model consists of two steel tubes. The 1st layer outer steel tube is made from stainless steel with an outer diameter of $114 \mathrm{~mm}$ with a tube thickness of $1.88 \mathrm{~mm}$. On the other hand, the second inner steel tube is made from carbon steel and an outer diameter of $89 \mathrm{~mm}$ and a thickness of $2.01 \mathrm{~mm}$. Furthermore, there will be one Normal Strength Concrete (NSC) fill sandwich layer with a compressive strength of 55.3MPa between the outer and the inner steel tubes. On the contrary, the inner carbon steel tube will be hollow/unfilled. Moreover, all the specimens had a standard length of $1800 \mathrm{~mm}$.

This design in figure 3 by [19] represented simulation numbers 13 to 18 with variations in magnitude of axial load, drop height and impact energy. For example, simulations number 13 and 14 were axially load with a magnitude of $142 \mathrm{kN}$, the drop height has been set at $3 \mathrm{~m}$ and the impact energy will be 6kJ. While simulation numbers 15 and 16 were not axially loaded, the drop height was set at $5 \mathrm{~m}$ and the impact energy will be around 10kJ. Furthermore, simulation numbers 17 and 18 were axially loaded with a magnitude of $237 \mathrm{kN}$, the drop height was set at $7 \mathrm{~m}$ and the impact energy will be $14 \mathrm{~kJ}$. Moreover, the drop mass had the same magnitude for all the simulations with a value of $203.7 \mathrm{Kg}$. Finally, the geometry of the bottom surface of the drop hammer indenter is rectangular and with a parameter of $30 \mathrm{~mm}$ by $80 \mathrm{~mm}$. 
1st concrete sandwich layer

- Normal Strength Concrete

(NSC) with compressive strength $=55.3 \mathrm{Mpa}$

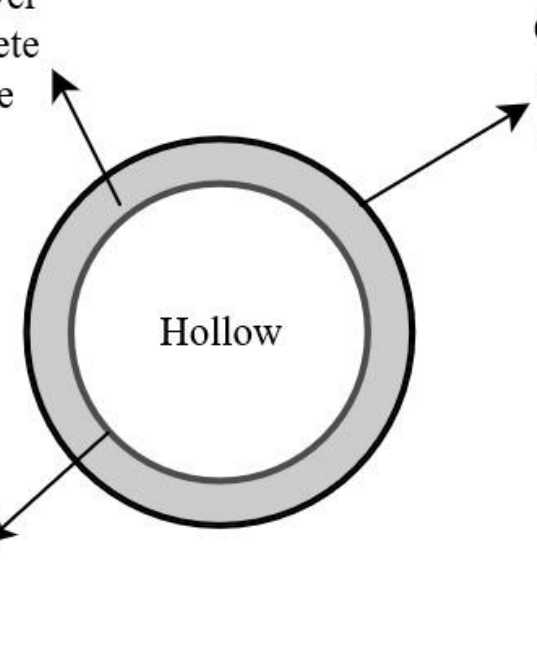

Outer 1st layer Stainless steel tube with an outer diameter $=114 \mathrm{~mm}$ and $\mathrm{ts}=1.88 \mathrm{~mm}$

Inner 2nd layer Carbon steel tube with an outer diameter $=89 \mathrm{~mm}$ and ts $=2.01 \mathrm{~mm}$

Figure 3. Schematic sketch of the CFDST cross section and material properties for specimens with hollowness ratio of 0.81 by [19].

This subsection of the numerical analysis will present the meshing and elements for Concrete Filled Double skin Steel Tubular members under transverse impact load investigation in accordance to the properties stated by [19] in terms of CFDST element, supports, drop hammer and FE model. The numerical meshing and elements of the first modeling analysis part for the Concrete Filled Double skin Steel Tubular members under transverse impact load investigation has been in accordance to the properties stated by [19]. Accordingly, the mesh for both the outer first layer stainless steel tube and the inner second layer carbon steel tube were simulated using S4R 4-node shell elements. While the mesh for concrete fill sandwich between the outer and the inner steel tubes was simulated using C3D8R 8-node solid element. With reference to [19], the mesh for supports has been built using R3D4 4-node quadrilateral rigid element. Again, as recommended by [19], the mesh for drop hammer were built using R3D4 4-node quadrilateral rigid element.

\subsection{First Proposed modification by Abdel Rahim (2021) - CFDST with internal carbon steel tube filled with NSC}

The second stage of the numerical analysis involves the first proposed modification by [1-3] on CFDST specimens which were carried out by [19]. This was done by filling the internal carbon steel tube with Normal Strength Concrete (NSC) and evaluating the structural behavior under impact loading. Moreover, the results obtained [1-3] has been compared with the experimental results achieved by [19] to determine the percentage of increase in the impact resistivity of the first proposed design. As shown in Table 5, the second stage of this study consists of eighteen numerical models (simulation numbers 19 to 36) has been evaluated with a minor modification (filling the internal carbon steel tube with NSC) on the tested specimens by [19]. Again, three main variables have been evaluated (diameter of internal carbon steel tube, magnitude of axial load and drop height). In addition, Table 5 presents a detailed list of geometrical properties, cross sectional dimensions and impact loading conditions for the first proposed modification on the CFDST specimens carried out by [19]. Besides, the list which presented in Table 5 includes details of the simulation numbers, specimens tag numbers, type of modification for this stage, diameter and thickness of the steel tubes, length of the specimens, magnitude of axial load, drop heights, impact mass, impact energy and geometry and size of indenter.

Table 5. List of geometrical properties, cross sectional dimensions and impact loading conditions for CFDST specimens with First Proposed modification by [1-3]. 


\begin{tabular}{|c|c|c|c|c|c|c|c|c|c|c|c|c|c|}
\hline \multirow{2}{*}{ 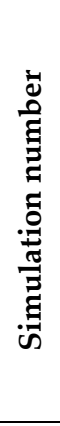 } & \multirow[t]{2}{*}{$\begin{array}{c}\text { Specimen } \\
\text { Tag } \\
\text { number }\end{array}$} & \multicolumn{2}{|c|}{$\begin{array}{c}\text { Outer } \\
\text { 1st layer } \\
\text { Stainless } \\
\text { Steel tube }\end{array}$} & \multicolumn{2}{|c|}{$\begin{array}{c}\text { Inner } \\
\text { 2nd layer } \\
\text { Carbon } \\
\text { Steel tube }\end{array}$} & \multicolumn{2}{|c|}{$\begin{array}{c}\text { Inner } \\
\text { 3rd } \\
\text { layer } \\
\text { Car- } \\
\text { bon } \\
\text { Steel } \\
\text { tube }\end{array}$} & \multirow[t]{2}{*}{$\underset{\mathfrak{\Xi}}{\stackrel{\Xi \Xi}{\Xi}}$} & \multirow[t]{2}{*}{ 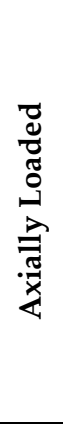 } & \multirow{2}{*}{ 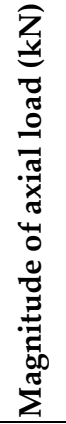 } & \multirow[t]{2}{*}{$\underset{\mathbf{I}}{\underline{\mathbf{E}}}$} & \multirow[t]{2}{*}{ 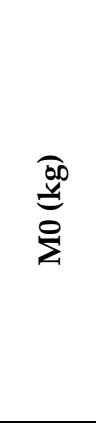 } & \multirow[t]{2}{*}{ శ్ర్య } \\
\hline & & $\begin{array}{l}\mathfrak{\Xi} \\
\mathfrak{\Xi} \\
\end{array}$ & $\underset{\infty}{\mathfrak{\Xi}}$ & ఏ્ఏ & 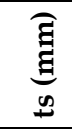 & 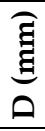 & $\underset{\Xi}{\Xi}$ & & & & & & \\
\hline 19 & L-3-0-a-M1 & 114 & 1.88 & 48 & 2.52 & - & - & \multirow{18}{*}{$\underset{\infty}{8}$} & No & 0 & 3 & 203.7 & 6 \\
\hline 20 & L-3-0-b-M1 & 114 & 1.88 & 48 & 2.52 & - & - & & No & 0 & 3 & 203.7 & 6 \\
\hline 21 & L-5-0.5-a-M1 & 114 & 1.88 & 48 & 2.52 & - & - & & Yes & 343 & 5 & 203.7 & 10 \\
\hline 22 & L-5-0.5-b-M1 & 114 & 1.88 & 48 & 2.52 & - & - & & Yes & 343 & 5 & 203.7 & 10 \\
\hline 23 & L-7-0.3-a-M1 & 114 & 1.88 & 48 & 2.52 & - & - & & Yes & 206 & 7 & 203.7 & 14 \\
\hline 24 & L-7-0.3-b-M1 & 114 & 1.88 & 48 & 2.52 & - & - & & Yes & 206 & 7 & 203.7 & 14 \\
\hline 25 & M-3-0.5-a-M1 & 114 & 1.88 & 76 & 2.01 & - & - & & Yes & 317 & 3 & 203.7 & 6 \\
\hline 26 & M-3-0.5-b-M1 & 114 & 1.88 & 76 & 2.01 & - & - & & Yes & 317 & 3 & 203.7 & 6 \\
\hline 27 & M-5-0.3-a-M1 & 114 & 1.88 & 76 & 2.01 & - & - & & Yes & 190 & 5 & 203.7 & 10 \\
\hline 28 & M-5-0.3-b-M1 & 114 & 1.88 & 76 & 2.01 & - & - & & Yes & 190 & 5 & 203.7 & 10 \\
\hline 29 & M-7-0-a-M1 & 114 & 1.88 & 76 & 2.01 & - & - & & No & 0 & 7 & 203.7 & 14 \\
\hline 30 & M-7-0-b-M1 & 114 & 1.88 & 76 & 2.01 & - & - & & No & 0 & 7 & 203.7 & 14 \\
\hline 31 & H-3-0.3-a-M1 & 114 & 1.88 & 89 & 2.01 & - & - & & Yes & 142 & 3 & 203.7 & 6 \\
\hline 32 & H-3-0.3-b-M1 & 114 & 1.88 & 89 & 2.01 & - & - & & Yes & 142 & 3 & 203.7 & 6 \\
\hline 33 & H-5-0-a-M1 & 114 & 1.88 & 89 & 2.01 & - & - & & No & 0 & 5 & 203.7 & 10 \\
\hline 34 & H-5-0-b-M1 & 114 & 1.88 & 89 & 2.01 & - & - & & No & 0 & 5 & 203.7 & 10 \\
\hline 35 & H-7-0.5-a-M1 & 114 & 1.88 & 89 & 2.01 & - & - & & Yes & 237 & 7 & 203.7 & 14 \\
\hline 36 & H-7-0.5-b-M1 & 114 & 1.88 & 89 & 2.01 & - & - & & Yes & 237 & 7 & 203.7 & 14 \\
\hline
\end{tabular}

Modification 1 - Fill Inner 2nd layer Carbon Steel tube with NSC

Impactor/Indenter geometry and size - drop hammer with $30 \mathrm{~mm} \times 80 \mathrm{~mm}$ rectangular bottom surface.

A schematic drawing has been shown in Figure 4 of the CFDST cross section with first modification and material properties for specimens with $48 \mathrm{~mm}$ outer diameter of the internal tube. As can be seen in Figure 4, the model consisted of two steel tubes. The 1st layer outer steel tube is made from stainless steel with an outer diameter of $114 \mathrm{~mm}$ with a tube thickness of $1.88 \mathrm{~mm}$. On the other hand, the second inner steel tube is made from carbon steel and an outer diameter of $48 \mathrm{~mm}$ and a thickness of $2.52 \mathrm{~mm}$. Furthermore, there will be one Normal Strength Concrete (NSC) fill sandwich layer with a compressive strength of 55.3MPa between the outer and the inner steel tubes. In addition, the inner carbon steel tube has been also filled with Normal Strength Concrete (NSC) with a compressive strength of 55.3MPa. Moreover, all the numerically analyzed specimens had a standard length of $1800 \mathrm{~mm}$.

This proposed modification design in figure 4 represented simulation numbers 19 to 24 with variations in magnitude of axial load, drop height and impact energy. For example, simulations number 19 and 20 were not axially load, the drop height was set at $3 \mathrm{~m}$ and the impact energy will be $6 \mathrm{~kJ}$. While simulation numbers 21 and 22 were axially loaded with a magnitude of $343 \mathrm{kN}$, the drop height was set at $5 \mathrm{~m}$ and the impact energy will be 
around 10kJ. Furthermore, simulation numbers 23 and 24 were axially loaded with a magnitude of $206 \mathrm{kN}$, the drop height was set at $7 \mathrm{~m}$ and the impact energy will be $14 \mathrm{~kJ}$. Moreover, the drop mass had the same magnitude for all the simulations with a value of $203.7 \mathrm{Kg}$. Finally, the geometry of the bottom surface of the drop hammer indenter is rectangular and with a parameter of $30 \mathrm{~mm}$ by $80 \mathrm{~mm}$.

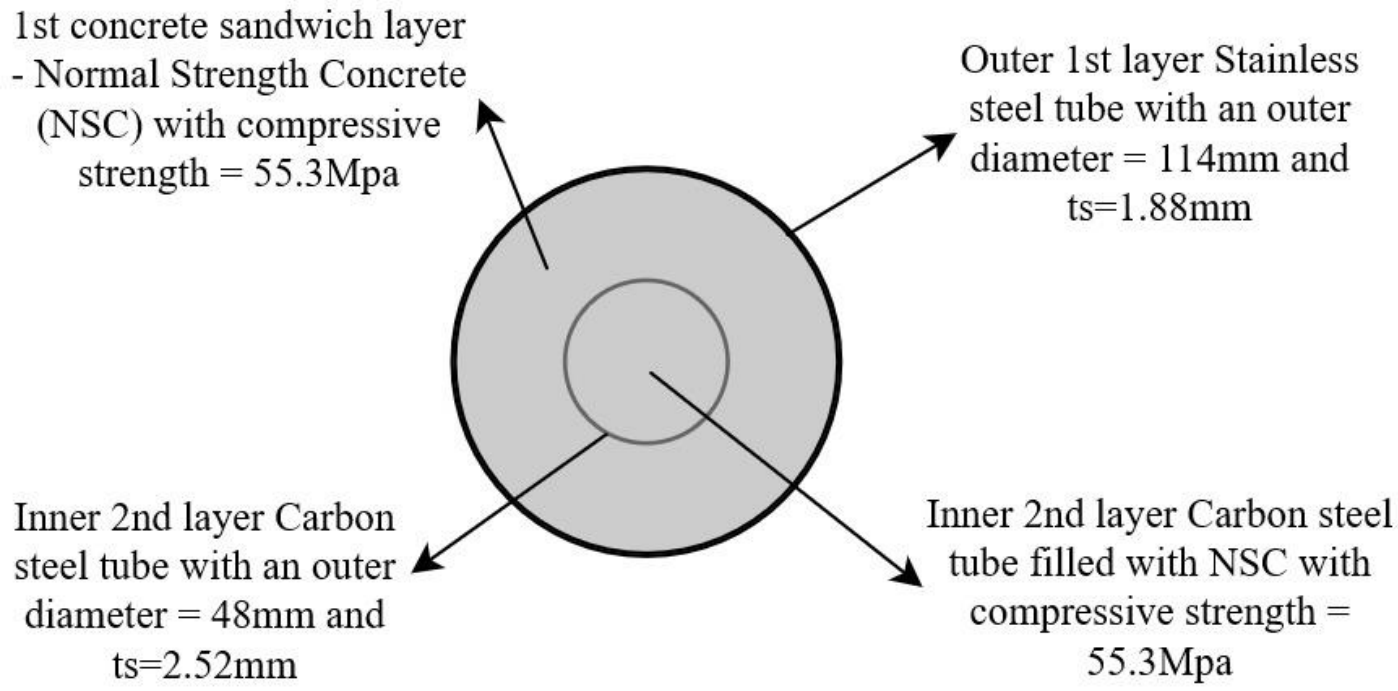

Figure 4. Schematic sketch of CFDST cross section with 1st modification by [1-3] and material properties for specimens with $48 \mathrm{~mm}$ outer diameter of the internal tube.

A schematic drawing has been shown in Figure 5 of the CFDST cross section with first modification and material properties for specimens with $76 \mathrm{~mm}$ outer diameter of the internal tube. As can be seen in Figure 5, the model consisted of two steel tubes. The first layer outer steel tube is made from stainless steel with an outer diameter of $114 \mathrm{~mm}$ with a tube thickness of $1.88 \mathrm{~mm}$. On the other hand, the second inner steel tube is made from carbon steel and an outer diameter of $76 \mathrm{~mm}$ and a thickness of $2.01 \mathrm{~mm}$. Furthermore, there will be one Normal Strength Concrete (NSC) fill sandwich layer with a compressive strength of 55.3MPa between the outer and the inner steel tubes. In addition, the inner carbon steel tube has been also filled with Normal Strength Concrete (NSC) with a compressive strength of 55.3MPa. Moreover, all the numerically analyzed specimens had a standard length of $1800 \mathrm{~mm}$.

This design modification in figure 5 will represent simulation numbers 25 to 30 with variations in magnitude of axial load, drop height and impact energy. For example, simulations number 25 and 26 will be axially load with a magnitude of $317 \mathrm{kN}$, the drop height will be set at $3 \mathrm{~m}$ and the impact energy will be $6 \mathrm{~kJ}$. While simulation numbers 27 and 28 will be axially loaded with a magnitude of $190 \mathrm{kN}$, the drop height will be set at $5 \mathrm{~m}$ and the impact energy will be around 10kJ. Furthermore, simulation numbers 29 and 30 will not be axially loaded, the drop height will be set at $7 \mathrm{~m}$ and the impact energy will be $14 \mathrm{~kJ}$. Moreover, the drop mass will have the same magnitude for all the simulations with a value of $203.7 \mathrm{Kg}$. Finally, the geometry of the bottom surface of the drop hammer indenter is rectangular and with a parameter of $30 \mathrm{~mm}$ by $80 \mathrm{~mm}$. 
1st concrete sandwich layer

- Normal Strength Concrete

(NSC) with compressive strength $=55.3 \mathrm{Mpa}$
Inner 2nd layer Carbon steel tube with an outer diameter $=76 \mathrm{~mm}$ and $\mathrm{ts}=2.01 \mathrm{~mm}$
Outer 1st layer Stainless steel tube with an outer diameter $=114 \mathrm{~mm}$ and ts $=1.88 \mathrm{~mm}$

Figure 5. Schematic sketch of CFDST cross section with 1st modification by [1-3] and material properties for specimens with $76 \mathrm{~mm}$ outer diameter of the internal tube.

A schematic drawing has been shown in Figure 6 of the CFDST cross section with first modification and material properties for specimens with $89 \mathrm{~mm}$ outer diameter of the internal tube. As can be seen in Figure 6, the model consisted of two steel tubes. The first layer outer steel tube is made from stainless steel with an outer diameter of $114 \mathrm{~mm}$ with a tube thickness of $1.88 \mathrm{~mm}$. On the other hand, the second inner steel tube is made from carbon steel and an outer diameter of $89 \mathrm{~mm}$ and a thickness of $2.01 \mathrm{~mm}$. Furthermore, there will be one Normal Strength Concrete (NSC) fill sandwich layer with a compressive strength of 55.3MPa between the outer and the inner steel tubes. In addition, the inner carbon steel tube was also filled with Normal Strength Concrete (NSC) with a compressive strength of 55.3MPa. Moreover, all the numerically analyzed specimens had a standard length of $1800 \mathrm{~mm}$.

This design modification in figure 6 will represent simulation numbers 31 to 36 with variations in magnitude of axial load, drop height and impact energy. For example, simulations number 31 and 32 will be axially load with a magnitude of $142 \mathrm{kN}$, the drop height will be set at $3 \mathrm{~m}$ and the impact energy will be $6 \mathrm{~kJ}$. While simulation numbers 33 and 34 will not be axially loaded, the drop height will be set at $5 \mathrm{~m}$ and the impact energy will be around 10kJ. Furthermore, simulation numbers 35 and 36 will be axially loaded with a magnitude of $237 \mathrm{kN}$, the drop height will be set at $7 \mathrm{~m}$ and the impact energy will be $14 \mathrm{~kJ}$. Moreover, the drop mass will have the same magnitude for all the simulations with a value of $203.7 \mathrm{Kg}$. Additionally, the geometry of the bottom surface of the drop hammer indenter is rectangular and with a parameter of $30 \mathrm{~mm}$ by $80 \mathrm{~mm}$. 
1st concrete sandwich layer

- Normal Strength Concrete

(NSC) with compressive strength $=55.3 \mathrm{Mpa}$

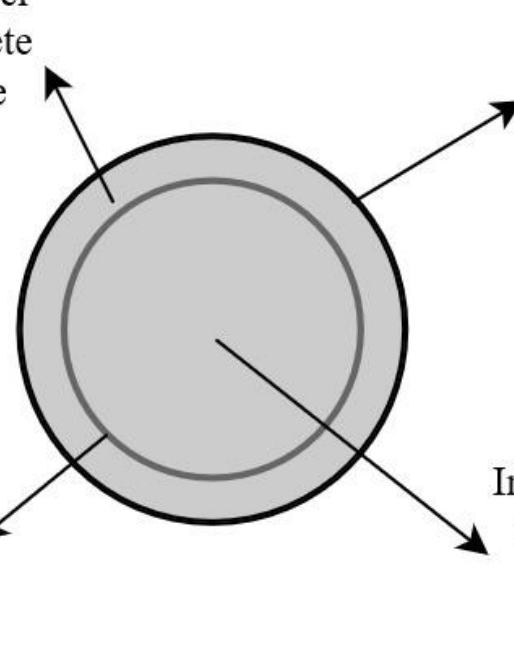

Outer 1st layer Stainless steel tube with an outer diameter $=114 \mathrm{~mm}$ and $\mathrm{ts}=1.88 \mathrm{~mm}$

Inner 2nd layer Carbon steel tube with an outer diameter $=89 \mathrm{~mm}$ and ner 2nd layer Carbon steel tube filled with NSC with compressive strength $=$ ts $=2.01 \mathrm{~mm}$ $55.3 \mathrm{Mpa}$

Figure 6. Schematic sketch of CFDST cross section with 1st modification by [1-3] and material properties for specimens with $89 \mathrm{~mm}$ outer diameter of the internal tube.

This subsection of the numerical analysis will present the meshing and elements for Concrete Filled Double skin Steel Tubular column members with internal carbon steel tube filled with NSC under transverse impact load investigation in accordance to the properties stated by [19]. In addition, the meshing illustrations will be shown in terms of CFDST elemenet, supports, drop hammer and FE model. The numerical meshing and elements of the second modeling analysis part for the proposed modification 1 by [1-3] CFDST with internal carbon steel tube filled with NSC under transverse impact load investigation has been as follows:

- The mesh for both the outer first layer stainless steel tube and the inner second layer carbon steel tube has been simulated using S4R 4-node shell elements.

- The mesh for both the first Normal Strength Concrete (NSC) fill sandwich layer and the inner second Normal Strength Concrete (NSC) fill sandwich layer (NSC) has been simulated using C3D8R 8-node solid element.

With reference to [19], the mesh for supports has been built using R3D4 4-node quadrilateral rigid element. Again, as recommended by [19], the mesh for drop hammer were built using R3D4 4-node quadrilateral rigid element.

\subsection{Second proposed modification by Abdel Rahim (2021) - CFDST with 1st sandwich layer filled with UHPFRC}

The third stage of the numerical analysis involves the second proposed modification by [1-3] on CFDST specimens which were carried out by [19]. This is by filling the 1st sandwich layer between the outer and the internal steel tubes with Ultra High-Performance Fiber Reinforced Polymer (UHPFRC) and evaluating the structural behavior under impact loading. Moreover, the results obtained by [1-3] has been compared with the experimental results achieved by [19] to determine the percentage of increase in the impact resistivity of the second proposed design. As shown in Table 6, the third stage of this study consisted of eighteen numerical models (simulation numbers 37 to 54) were evaluated with a minor modification (filling the internal carbon steel tube with UHPFRC) on the tested specimens by [19]. Again, three main variables were evaluated (diameter of internal carbon steel tube, magnitude of axial load and drop height). In addition, Table 6 presents a detailed list of geometrical properties, cross sectional dimensions and impact loading 
conditions for the second proposed modification on the CFDST specimens carried out by [19]. Besides, the list which presented in Table 6 includes details of the simulation numbers, specimens tag numbers, type of modification for this stage, diameter and thickness of the steel tubes, length of the specimens, magnitude of axial load, drop heights, impact mass, impact energy and geometry and size of indenter.

Table 6. List of geometrical properties, cross sectional dimensions and impact loading conditions for CFDST specimens with second proposed modification by [1-3].

\begin{tabular}{|c|c|c|c|c|c|c|c|c|c|c|c|c|c|}
\hline \multirow[t]{2}{*}{ 泀 } & \multirow[t]{2}{*}{$\begin{array}{c}\text { Specimen } \\
\text { Tag } \\
\text { number }\end{array}$} & \multicolumn{2}{|c|}{$\begin{array}{c}\text { Outer } \\
\text { 1st layer } \\
\text { Stainless } \\
\text { Steel tube }\end{array}$} & \multicolumn{2}{|c|}{$\begin{array}{l}\text { Inner } \\
\text { 2nd layer } \\
\text { Carbon } \\
\text { Steel tube }\end{array}$} & \multicolumn{2}{|c|}{$\begin{array}{c}\text { Inner } \\
\text { 3rd } \\
\text { layer } \\
\text { Car- } \\
\text { bon } \\
\text { Steel } \\
\text { tube }\end{array}$} & \multirow[t]{2}{*}{ 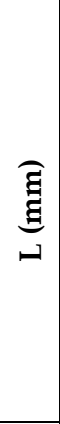 } & \multirow[t]{2}{*}{ 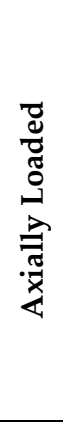 } & \multirow{2}{*}{ 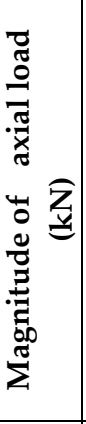 } & \multirow[t]{2}{*}{$\begin{array}{l}\underset{\boldsymbol{\Xi}}{\boldsymbol{I}} \\
\end{array}$} & \multirow[t]{2}{*}{$\begin{array}{l}\text { OD } \\
\stackrel{y}{=} \\
\sum\end{array}$} & \multirow[t]{2}{*}{ 氕 } \\
\hline & & $\begin{array}{l}\hat{\Xi} \\
\mathfrak{\Xi} \\
\end{array}$ & 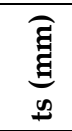 & ఏ & $\underset{\infty}{\mathfrak{g}}$ & $\underset{\mathfrak{\Xi}}{\mathfrak{\Xi}}$ & 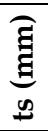 & & & & & & \\
\hline 37 & L-3-0-a-M2 & 114 & 1.88 & 48 & 2.52 & - & - & \multirow{18}{*}{ 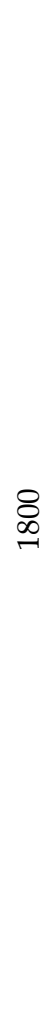 } & No & 0 & 3 & 203.7 & 6 \\
\hline 38 & L-3-0-b-M2 & 114 & 1.88 & 48 & 2.52 & - & - & & No & 0 & 3 & 203.7 & 6 \\
\hline 39 & L-5-0.5-a-M2 & 114 & 1.88 & 48 & 2.52 & - & - & & Yes & 343 & 5 & 203.7 & 10 \\
\hline 40 & L-5-0.5-b-M2 & 114 & 1.88 & 48 & 2.52 & - & - & & Yes & 343 & 5 & 203.7 & 10 \\
\hline 41 & L-7-0.3-a-M2 & 114 & 1.88 & 48 & 2.52 & - & - & & Yes & 206 & 7 & 203.7 & 14 \\
\hline 42 & L-7-0.3-b-M2 & 114 & 1.88 & 48 & 2.52 & - & - & & Yes & 206 & 7 & 203.7 & 14 \\
\hline 43 & M-3-0.5-a-M2 & 114 & 1.88 & 76 & 2.01 & - & - & & Yes & 317 & 3 & 203.7 & 6 \\
\hline 44 & M-3-0.5-b-M2 & 114 & 1.88 & 76 & 2.01 & - & - & & Yes & 317 & 3 & 203.7 & 6 \\
\hline 45 & M-5-0.3-a-M2 & 114 & 1.88 & 76 & 2.01 & - & - & & Yes & 190 & 5 & 203.7 & 10 \\
\hline 46 & M-5-0.3-b-M2 & 114 & 1.88 & 76 & 2.01 & - & - & & Yes & 190 & 5 & 203.7 & 10 \\
\hline 47 & M-7-0-a-M2 & 114 & 1.88 & 76 & 2.01 & - & - & & No & 0 & 7 & 203.7 & 14 \\
\hline 48 & M-7-0-b-M2 & 114 & 1.88 & 76 & 2.01 & - & - & & No & 0 & 7 & 203.7 & 14 \\
\hline 49 & H-3-0.3-a-M2 & 114 & 1.88 & 89 & 2.01 & - & - & & Yes & 142 & 3 & 203.7 & 6 \\
\hline 50 & H-3-0.3-b-M2 & 114 & 1.88 & 89 & 2.01 & - & - & & Yes & 142 & 3 & 203.7 & 6 \\
\hline 51 & H-5-0-a-M2 & 114 & 1.88 & 89 & 2.01 & - & - & & No & 0 & 5 & 203.7 & 10 \\
\hline 52 & H-5-0-b-M2 & 114 & 1.88 & 89 & 2.01 & - & - & & No & 0 & 5 & 203.7 & 10 \\
\hline 53 & H-7-0.5-a-M2 & 114 & 1.88 & 89 & 2.01 & - & - & & Yes & 237 & 7 & 203.7 & 14 \\
\hline 54 & H-7-0.5-b-M2 & 114 & 1.88 & 89 & 2.01 & - & - & & Yes & 237 & 7 & 203.7 & 14 \\
\hline
\end{tabular}

Modification 2 - (1) Filling the sandwich layer between the Outer 1st layer Stainless Steel tube and the Inner 2nd layer Carbon Steel tube with UHPFRC \& (2) keeping the Inner 2nd layer Carbon Steel tube hollow without concrete fill.

Impactor/Indenter geometry and size - drop hammer with $30 \mathrm{~mm} \times 80 \mathrm{~mm}$ rectangular bottom surface.

A schematic drawing has been shown in Figure 7 of the CFDST cross section with second modification and material properties for specimens with hollowness ratio of 0.44 . As can be seen in Figure 7, the model consisted of two steel tubes. The 1st layer outer steel tube is made from stainless steel with an outer diameter of $114 \mathrm{~mm}$ with a tube thickness of $1.88 \mathrm{~mm}$. On the other hand, the second inner steel tube is made from carbon steel and an outer diameter of $48 \mathrm{~mm}$ and a thickness of $2.52 \mathrm{~mm}$. Furthermore, there has been one Ultra High-Performance Fiber Reinforced Concrete (UHPFRC) fill sandwich layer with a 
compressive strength of $152 \mathrm{MPa}$ between the outer and the inner steel tubes with reference to the material properties used by [15-16]. On the contrary, the inner carbon steel tube was hollow/unfilled. Moreover, all the numerically analyzed specimens had a standard length of $1800 \mathrm{~mm}$.

This design modification in figure 7 will represent simulation numbers 37 to 42 with variations in magnitude of axial load, drop height and impact energy. For example, simulations number 37 and 38 will be axially load with a magnitude of $142 \mathrm{kN}$, the drop height will be set at $3 \mathrm{~m}$ and the impact energy will be $6 \mathrm{~kJ}$. While simulation numbers 39 and 40 will not be axially loaded, the drop height will be set at $5 \mathrm{~m}$ and the impact energy will be around 10kJ. Furthermore, simulation numbers 41 and 42 will be axially loaded with a magnitude of $237 \mathrm{kN}$, the drop height will be set at $7 \mathrm{~m}$ and the impact energy will be $14 \mathrm{~kJ}$. Moreover, the drop mass will have the same magnitude for all the simulations with a value of $203.7 \mathrm{Kg}$. Additionally, the geometry of the bottom surface of the drop hammer indenter is rectangular and with a parameter of $30 \mathrm{~mm}$ by $80 \mathrm{~mm}$.

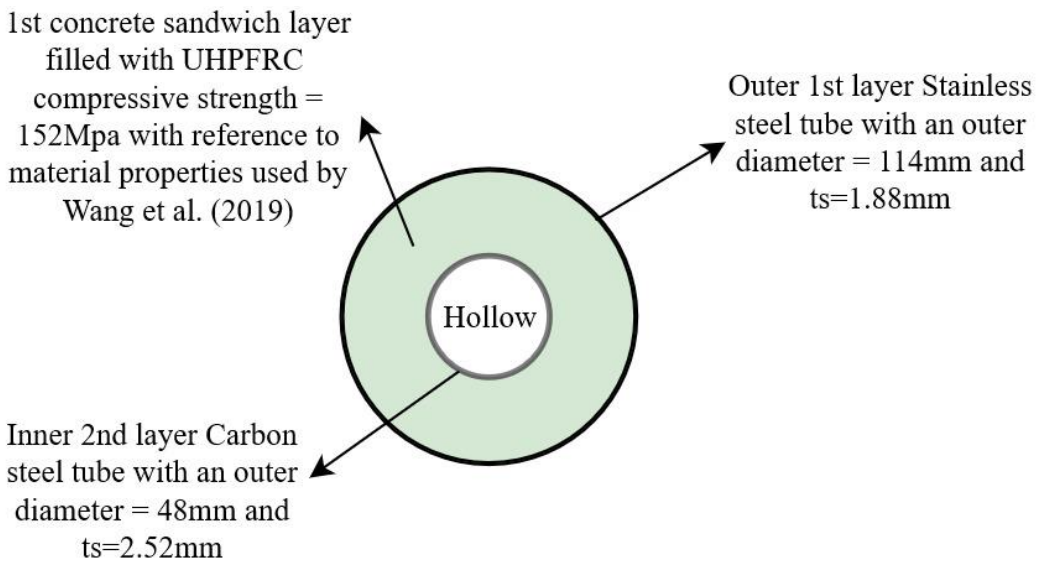

Figure 7. Schematic sketch of CFDST cross section with 2nd modification by [1-3] and material properties for specimens with hollowness ratio of 0.44 .

A schematic drawing has been shown in Figure 8 of the CFDST cross section with second modification and material properties for specimens with hollowness ratio of 0.69. As can be seen in Figure 8, the model consisted from two steel tubes. The 1st layer outer steel tube is made from stainless steel with an outer diameter of $114 \mathrm{~mm}$ with a tube thickness of $1.88 \mathrm{~mm}$. On the other hand, the second inner steel tube is made from carbon steel and an outer diameter of $76 \mathrm{~mm}$ and a thickness of $2.01 \mathrm{~mm}$. Furthermore, there has been one Ultra High-Performance Fiber Reinforced Concrete (UHPFRC) fill sandwich layer with a compressive strength of $152 \mathrm{MPa}$ between the outer and the inner steel tubes with reference to the material properties used by [15-16]. On the contrary, the inner carbon steel tube was hollow/unfilled. Moreover, all the numerically analyzed specimens had a standard length of $1800 \mathrm{~mm}$.

This design modification in figure 8 represented simulation numbers 43 to 48 with variations in magnitude of axial load, drop height and impact energy. For example, simulations number 43 and 44 were axially load with a magnitude of $317 \mathrm{kN}$, the drop height has been set at $3 \mathrm{~m}$ and the impact energy will be $6 \mathrm{~kJ}$. While simulation numbers 45 and 46 has been axially loaded with a magnitude of $190 \mathrm{kN}$, the drop height has been set at $5 \mathrm{~m}$ and the impact energy will be around 10kJ. Furthermore, simulation numbers 47 and 48 were not axially loaded, the drop height was set at $7 \mathrm{~m}$ and the impact energy will be $14 \mathrm{~kJ}$. Moreover, the drop mass had the same magnitude for all the simulations with a value of $203.7 \mathrm{Kg}$. Finally, the geometry of the bottom surface of the drop hammer indenter is rectangular and with a parameter of $30 \mathrm{~mm}$ by $80 \mathrm{~mm}$. 
1st concrete sandwich layer

filled with UHPFRC

compressive strength
Inner 2nd layer Carbon
steel tube with an outer
diameter $=76 \mathrm{~mm}$ and
ts=2.01mm

Outer 1st layer Stainless steel tube with an outer diameter $=114 \mathrm{~mm}$ and $\mathrm{ts}=1.88 \mathrm{~mm}$

Figure 8. Schematic sketch of CFDST cross section with 2nd modification by [1-3] and material properties for specimens with hollowness ratio of 0.69 .

A schematic drawing has been shown in Figure 9 of the CFDST cross section with second modification and material properties for specimens with hollowness ratio of 0.81 . As can be seen in Figure 9, the model consisted of two steel tubes. The 1st layer outer steel tube is made from stainless steel with an outer diameter of $114 \mathrm{~mm}$ with a tube thickness of $1.88 \mathrm{~mm}$. On the other hand, the second inner steel tube is made from carbon steel and an outer diameter of $89 \mathrm{~mm}$ and a thickness of $2.01 \mathrm{~mm}$. Furthermore, there has been one Ultra High-Performance Fiber Reinforced Concrete (UHPFRC) fill sandwich layer with a compressive strength of $152 \mathrm{MPa}$ between the outer and the inner steel tubes with reference to the material properties used by [15-16]. On the contrary, the inner carbon steel tube was hollow/unfilled. Moreover, all the numerically analyzed specimens had a standard length of $1800 \mathrm{~mm}$.

This design modification in figure 9 has been represented in simulation numbers 49 to 54 with variations in magnitude of axial load, drop height and impact energy. For example, simulations number 49 and 50 were axially load with a magnitude of $142 \mathrm{kN}$, the drop height was set at $3 \mathrm{~m}$ and the impact energy will be $6 \mathrm{~kJ}$. While simulation numbers 51 and 52 were not axially loaded, the drop height was set at $5 \mathrm{~m}$ and the impact energy will be around $10 \mathrm{~kJ}$. Furthermore, simulation numbers 53 and 54 were axially loaded with a magnitude of $237 \mathrm{kN}$, the drop height was set at $7 \mathrm{~m}$ and the impact energy will be $14 \mathrm{~kJ}$. Moreover, the drop mass had the same magnitude for all the simulations with a value of $203.7 \mathrm{Kg}$. Finally, the geometry of the bottom surface of the drop hammer indenter is rectangular and with a parameter of $30 \mathrm{~mm}$ by $80 \mathrm{~mm}$. 


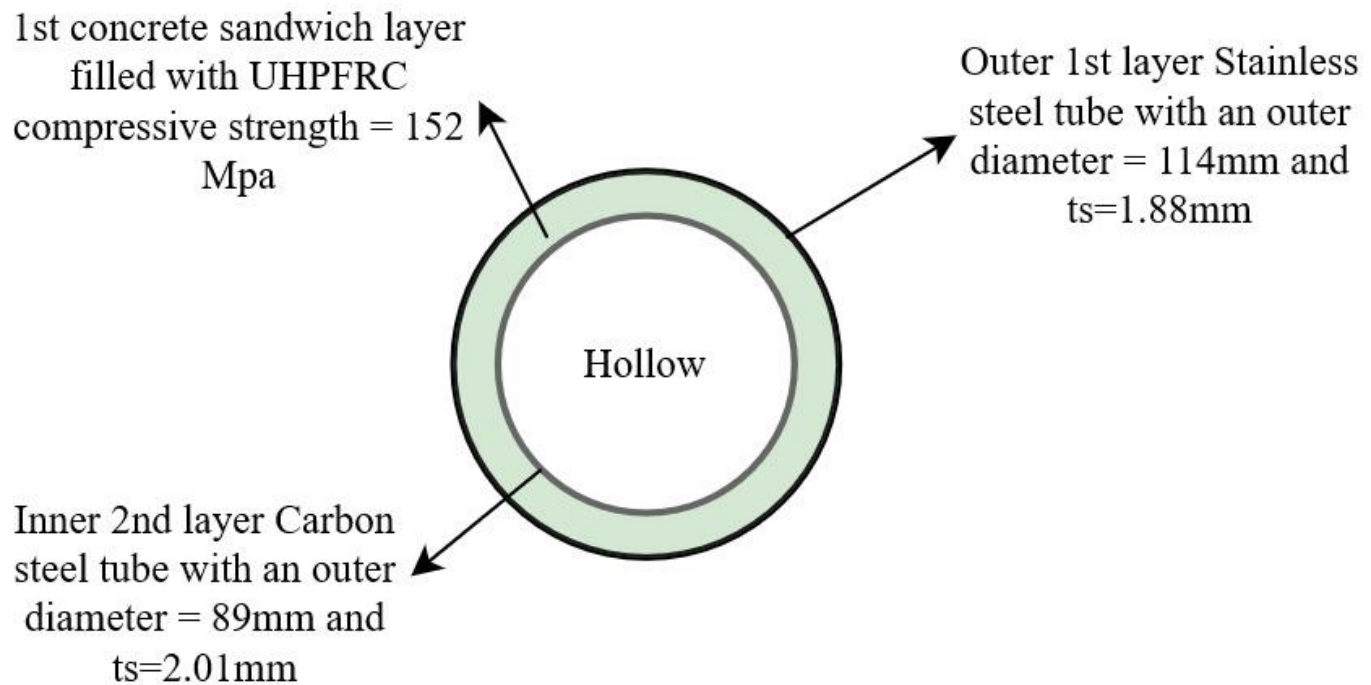

Figure 9. Schematic sketch of CFDST cross section with 2nd modification by [1-3] and material properties for specimens with hollowness ratio of 0.81 .

This subsection of the numerical analysis presented the meshing and elements for Concrete Filled Double skin Steel Tubular column members with 1st sandwich layer filled with UHPFRC under transverse impact load investigation in accordance to the properties stated by [19]. This is including CFDST elemenet, supports, drop hammer and FE model. The numerical meshing and elements of the third modeling analysis part for the proposed modification 2 - CFDST with 1st sandwich layer filled with UHPFRC under transverse impact load investigation has been as follows:

- The mesh for both the outer first layer stainless steel tube and the inner second layer carbon steel tube were simulated using S4R 4-node shell elements.

- The mesh for UHPFRC has been simulated using C3D8R 8-node solid element.

With reference to [19], the mesh for supports will be built using R3D4 4-node quadrilateral rigid element. Again, as recommended by [19], the mesh for drop hammer was built using R3D4 4-node quadrilateral rigid element.

\subsection{Third proposed modification by Abdel Rahim (2021) - CFDST with 1st sandwich layer filled with UHPFRC and internal carbon steel tube filled with NSC}

The fourth stage of the numerical analysis involves the third proposed modification on CFDST specimens which were carried out by [19]. This is by filling the 1st sandwich layer between the outer and the internal steel tubes with Ultra High-Performance Fiber Reinforced Polymer (UHPFRC). In addition, the internal carbon steel tube has been filled with Normal Strength Concrete (NSC). Afterwards, the structural behavior has been assisted under transverse impact loading. Moreover, the results obtained by [1-3] were compared with the experimental results achieved by [19] to determine the percentage of increase in the impact resistivity of the third proposed design. As shown in Table 7, the fourth stage of this study consisted of eighteen numerical models (simulation numbers 55 to 72). Again, three main variables were evaluated (diameter of internal carbon steel tube, magnitude of axial load and drop height). In addition, Table 7 presents a detailed list of geometrical properties, cross sectional dimensions and impact loading conditions for the third proposed modification on the CFDST specimens carried out by [19]. Besides, the list 
which presented in Table 7 includes details of the simulation numbers, specimens tag numbers, type of modification for this stage, diameter and thickness of the steel tubes, length of the specimens, magnitude of axial load, drop heights, impact mass, impact energy and geometry and size of indenter.

Table 7. List of geometrical properties, cross sectional dimensions and impact loading conditions for CFDST specimens with Third proposed modification by [1-3].

\begin{tabular}{|c|c|c|c|c|c|c|c|c|c|c|c|c|c|}
\hline \multirow{2}{*}{ 㔛 } & \multirow[t]{2}{*}{$\begin{array}{c}\text { Specimen } \\
\text { Tag } \\
\text { number }\end{array}$} & \multicolumn{2}{|c|}{$\begin{array}{c}\text { Outer } \\
\text { 1st layer } \\
\text { Stainless } \\
\text { Steel tube }\end{array}$} & \multicolumn{2}{|c|}{$\begin{array}{c}\text { Inner } \\
\text { 2nd layer } \\
\text { Carbon } \\
\text { Steel tube }\end{array}$} & \multicolumn{2}{|c|}{$\begin{array}{c}\text { Inner } \\
\text { 3rd } \\
\text { layer } \\
\text { Car- } \\
\text { bon } \\
\text { Steel } \\
\text { tube }\end{array}$} & \multirow[t]{2}{*}{$\underset{\Xi}{\underset{\Xi}{\Xi}}$} & \multirow[t]{2}{*}{ 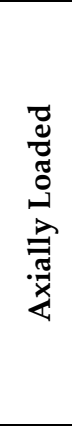 } & \multirow{2}{*}{ 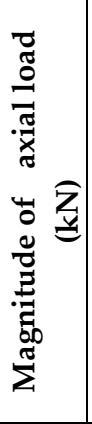 } & \multirow[t]{2}{*}{$\begin{array}{l}\text { छ } \\
\text { I }\end{array}$} & \multirow[t]{2}{*}{$\begin{array}{l}\text { कo } \\
\stackrel{0}{=} \\
\stackrel{0}{\Sigma}\end{array}$} & \multirow[t]{2}{*}{$\begin{array}{l}\text { ్ㅡㅁ } \\
\text { 오 }\end{array}$} \\
\hline & & 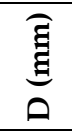 & 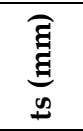 & ఏ & 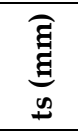 & 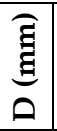 & $\underset{\infty}{\mathfrak{\Xi}}$ & & & & & & \\
\hline 55 & L-3-0-a-M3 & 114 & 1.88 & 48 & 2.52 & - & - & \multirow{18}{*}{ 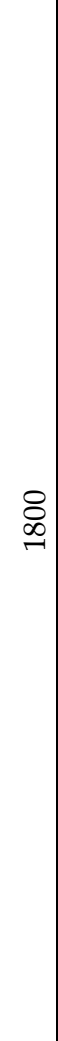 } & No & 0 & 3 & 203.7 & 6 \\
\hline 56 & L-3-0-b-M3 & 114 & 1.88 & 48 & 2.52 & - & - & & No & 0 & 3 & 203.7 & 6 \\
\hline 57 & L-5-0.5-a-M3 & 114 & 1.88 & 48 & 2.52 & - & - & & Yes & 343 & 5 & 203.7 & 10 \\
\hline 58 & L-5-0.5-b-M3 & 114 & 1.88 & 48 & 2.52 & - & - & & Yes & 343 & 5 & 203.7 & 10 \\
\hline 59 & L-7-0.3-a-M3 & 114 & 1.88 & 48 & 2.52 & - & - & & Yes & 206 & 7 & 203.7 & 14 \\
\hline 60 & L-7-0.3-b-M3 & 114 & 1.88 & 48 & 2.52 & - & - & & Yes & 206 & 7 & 203.7 & 14 \\
\hline 61 & M-3-0.5-a-M3 & 114 & 1.88 & 76 & 2.01 & - & - & & Yes & 317 & 3 & 203.7 & 6 \\
\hline 62 & M-3-0.5-b-M3 & 114 & 1.88 & 76 & 2.01 & - & - & & Yes & 317 & 3 & 203.7 & 6 \\
\hline 63 & M-5-0.3-a-M3 & 114 & 1.88 & 76 & 2.01 & - & - & & Yes & 190 & 5 & 203.7 & 10 \\
\hline 64 & M-5-0.3-b-M3 & 114 & 1.88 & 76 & 2.01 & - & - & & Yes & 190 & 5 & 203.7 & 10 \\
\hline 65 & M-7-0-a-M3 & 114 & 1.88 & 76 & 2.01 & - & - & & No & 0 & 7 & 203.7 & 14 \\
\hline 66 & M-7-0-b-M3 & 114 & 1.88 & 76 & 2.01 & - & - & & No & 0 & 7 & 203.7 & 14 \\
\hline 67 & H-3-0.3-a-M3 & 114 & 1.88 & 89 & 2.01 & - & - & & Yes & 142 & 3 & 203.7 & 6 \\
\hline 68 & H-3-0.3-b-M3 & 114 & 1.88 & 89 & 2.01 & - & - & & Yes & 142 & 3 & 203.7 & 6 \\
\hline 69 & H-5-0-a-M3 & 114 & 1.88 & 89 & 2.01 & - & - & & No & 0 & 5 & 203.7 & 10 \\
\hline 70 & H-5-0-b-M3 & 114 & 1.88 & 89 & 2.01 & - & - & & No & 0 & 5 & 203.7 & 10 \\
\hline 71 & H-7-0.5-a-M3 & 114 & 1.88 & 89 & 2.01 & - & - & & Yes & 237 & 7 & 203.7 & 14 \\
\hline 72 & H-7-0.5-b-M3 & 114 & 1.88 & 89 & 2.01 & - & - & & Yes & 237 & 7 & 203.7 & 14 \\
\hline
\end{tabular}

Modification 3 - (1) Filling the sandwich layer between the Outer 1st layer Stainless Steel tube and the Inner 2nd layer Carbon Steel tube with UHPFRC \& (2) Filling the Inner 2nd layer Carbon Steel tube with NSC. Impactor/Indenter geometry and size - drop hammer with $30 \mathrm{~mm} \times 80 \mathrm{~mm}$ rectangular bottom surface.

A schematic drawing has been shown in Figure 10 of the CFDST cross section with 3rd modification and material properties for specimens with $48 \mathrm{~mm}$ outer diameter of the internal tube. As can be seen in Figure 10, the model consisted of two steel tubes. The 1st layer outer steel tube is made from stainless steel with an outer diameter of $114 \mathrm{~mm}$ with a tube thickness of $1.88 \mathrm{~mm}$. On the other hand, the second inner steel tube is made from carbon steel and an outer diameter of $48 \mathrm{~mm}$ and a thickness of $2.52 \mathrm{~mm}$. Furthermore, there was one Ultra High-Performance Fiber Reinforced Concrete (UHPFRC) fill sandwich layer with a compressive strength of 152MPa between the outer and the inner steel tubes with reference to the material properties used by [15-16]. Additionally, the inner 
carbon steel tube was filled with Normal Strength Concrete (NSC) with a compressive strength of 55.3MPa. Moreover, all the numerically analyzed specimens had a standard length of $1800 \mathrm{~mm}$.

This proposed modification design in figure 10 represented simulation numbers 55 to 60 with variations in magnitude of axial load, drop height and impact energy. For example, simulations number 55 and 56 were not axially load, the drop height has been set at $3 \mathrm{~m}$ and the impact energy will be $6 \mathrm{~kJ}$. While simulation numbers 57 and 58 were axially loaded with a magnitude of $343 \mathrm{kN}$, the drop height was set at $5 \mathrm{~m}$ and the impact energy will be around 10kJ. Furthermore, simulation numbers 59 and 60 were axially loaded with a magnitude of $206 \mathrm{kN}$, the drop height was set at $7 \mathrm{~m}$ and the impact energy will be $14 \mathrm{~kJ}$. Moreover, the drop mass had the same magnitude for all the simulations with a value of $203.7 \mathrm{Kg}$. Finally, the geometry of the bottom surface of the drop hammer indenter is rectangular and with a parameter of $30 \mathrm{~mm}$ by $80 \mathrm{~mm}$.

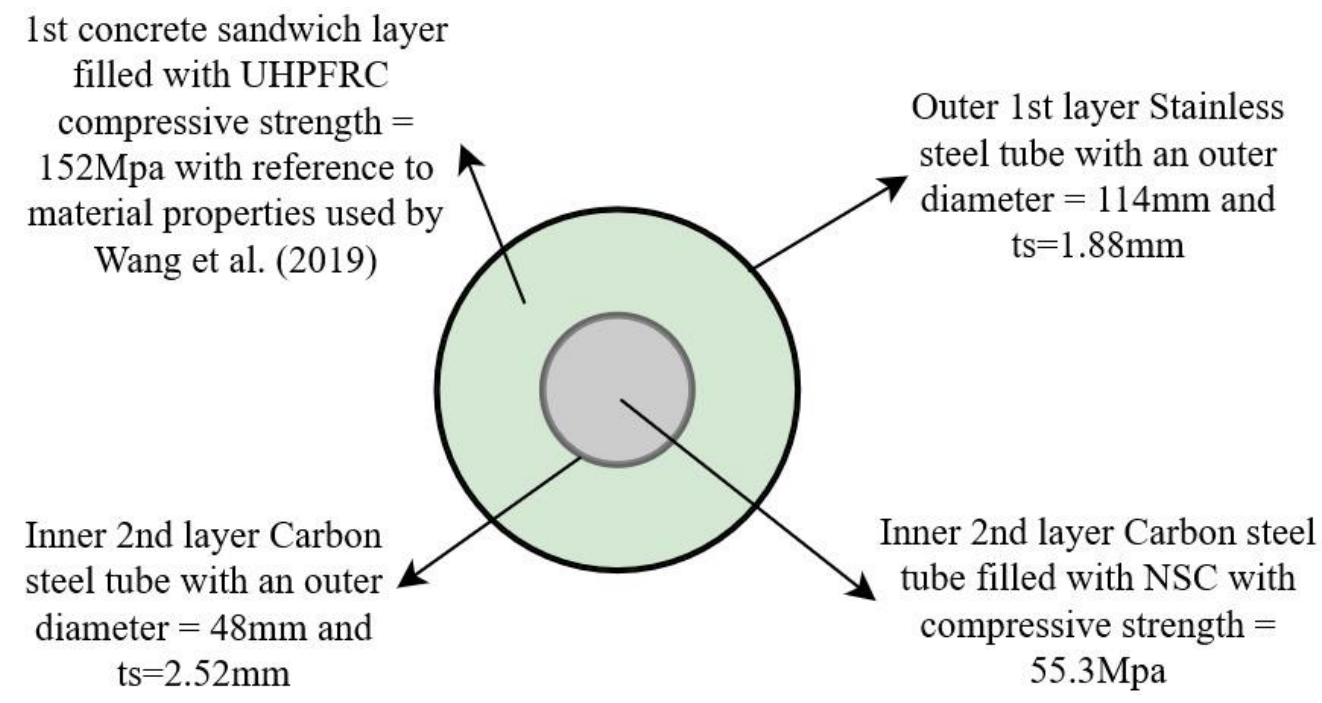

Figure 10. Schematic sketch of CFDST cross section with 3rd modification by [1-3] and material properties for specimens with $48 \mathrm{~mm}$ outer diameter of the internal tube.

A schematic drawing has been shown in Figure 11 of the CFDST cross section with 3rd modification and material properties for specimens with $76 \mathrm{~mm}$ outer diameter of the internal tube. As can be seen in Figure 11, the model consisted of two steel tubes. The 1st layer outer steel tube is made from stainless steel with an outer diameter of $114 \mathrm{~mm}$ with a tube thickness of $1.88 \mathrm{~mm}$. On the other hand, the second inner steel tube is made from carbon steel and an outer diameter of $76 \mathrm{~mm}$ and a thickness of $2.01 \mathrm{~mm}$. Furthermore, there was one Ultra High-Performance Fiber Reinforced Concrete (UHPFRC) fill sandwich layer with a compressive strength of $152 \mathrm{MPa}$ between the outer and the inner steel tubes with reference to the material properties used by [15-16]. Additionally, the inner carbon steel tube has been filled with Normal Strength Concrete (NSC) with a compressive strength of 55.3MPa. Moreover, all the numerically analyzed specimens had a standard length of $1800 \mathrm{~mm}$.

This design modification in figure 11 represented simulation numbers 61 to 66 with variations in magnitude of axial load, drop height and impact energy. For example, simulations number 61 and 62 were axially load with a magnitude of $317 \mathrm{kN}$, the drop height was set at $3 \mathrm{~m}$ and the impact energy will be $6 \mathrm{~kJ}$. While simulation numbers 63 and 64 were axially loaded with a magnitude of $190 \mathrm{kN}$, the drop height was set at $5 \mathrm{~m}$ and the impact energy will be around 10kJ. Furthermore, simulation numbers 65 and 66 were not axially loaded, the drop height was set at $7 \mathrm{~m}$ and the impact energy will be $14 \mathrm{~kJ}$. Moreover, the drop mass had the same magnitude for all the simulations with a value of $203.7 \mathrm{Kg}$. 
Finally, the geometry of the bottom surface of the drop hammer indenter is rectangular and with a parameter of $30 \mathrm{~mm}$ by $80 \mathrm{~mm}$.

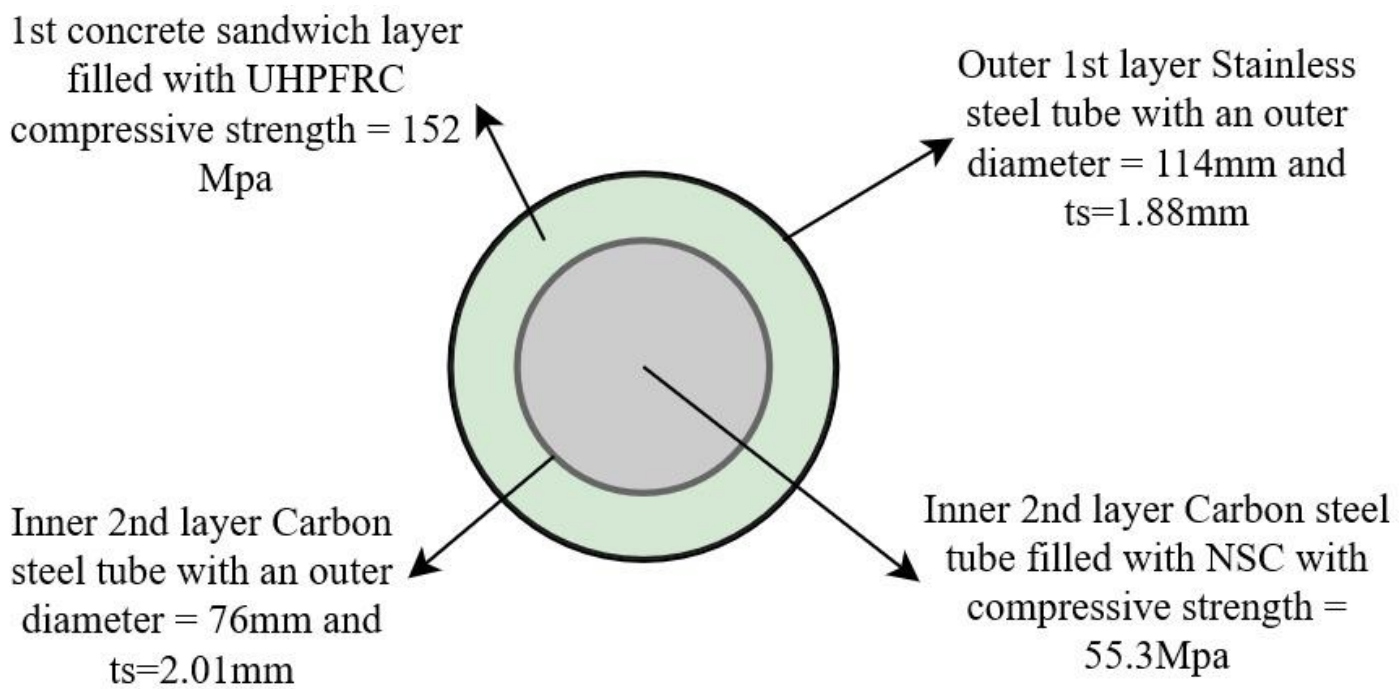

Figure 11. Schematic sketch of CFDST cross section with 3rd modification by [1-3] and material properties for specimens with $76 \mathrm{~mm}$ outer diameter of the internal tube.

A schematic drawing has been shown in Figure 12 of the CFDST cross section with third modification and material properties for specimens with $89 \mathrm{~mm}$ outer diameter of the internal tube. As can be seen in Figure 12, the model consisted of two steel tubes. The 1st layer outer steel tube is made from stainless steel with an outer diameter of $114 \mathrm{~mm}$ with a tube thickness of $1.88 \mathrm{~mm}$. On the other hand, the second inner steel tube is made from carbon steel and an outer diameter of $89 \mathrm{~mm}$ and a thickness of $2.01 \mathrm{~mm}$. Furthermore, there was one Ultra High-Performance Fiber Reinforced Concrete (UHPFRC) fill sandwich layer with a compressive strength of $152 \mathrm{MPa}$ between the outer and the inner steel tubes with reference to the material properties used by [15-16]. Additionally, the inner carbon steel tube was filled with Normal Strength Concrete (NSC) with a compressive strength of 55.3MPa. Moreover, all the numerically analyzed specimens had a standard length of $1800 \mathrm{~mm}$.

This design modification in figure 12 represented simulation numbers 67 to 72 with variations in magnitude of axial load, drop height and impact energy. For example, simulations number 67 and 68 were axially load with a magnitude of $142 \mathrm{kN}$, the drop height was set at $3 \mathrm{~m}$ and the impact energy will be $6 \mathrm{~kJ}$. While simulation numbers 69 and 70 were not axially loaded, the drop height was set at $5 \mathrm{~m}$ and the impact energy will be around 10kJ. Furthermore, simulation numbers 71 and 72 were axially loaded with a magnitude of $237 \mathrm{kN}$, the drop height was set at $7 \mathrm{~m}$ and the impact energy will be $14 \mathrm{~kJ}$. Moreover, the drop mass had the same magnitude for all the simulations with a value of $203.7 \mathrm{Kg}$. Finally, the geometry of the bottom surface of the drop hammer indenter is rectangular and with a parameter of $30 \mathrm{~mm}$ by $80 \mathrm{~mm}$. 
1st concrete sandwich layer

filled with UHPFRC

compressive strength $=152$

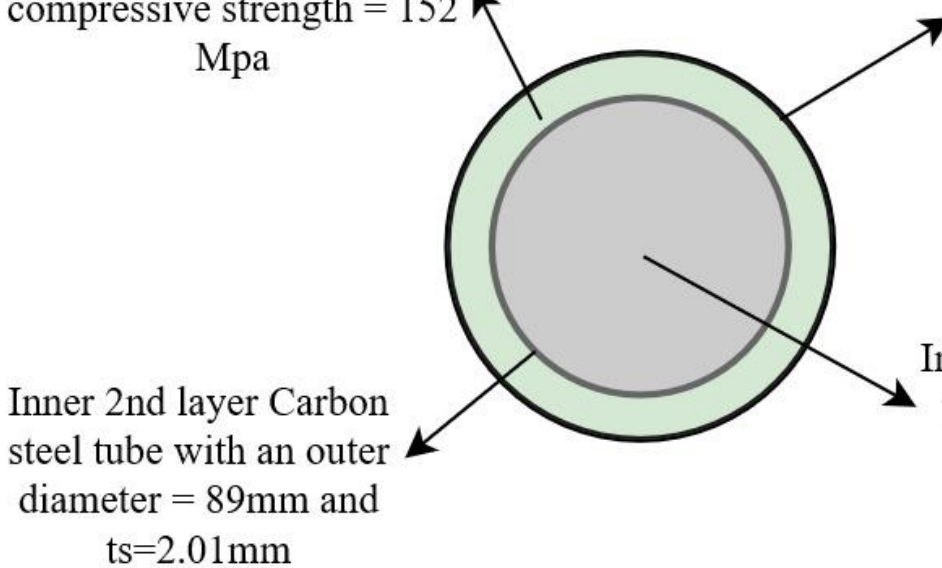

Outer 1st layer Stainless steel tube with an outer diameter $=114 \mathrm{~mm}$ and $\mathrm{ts}=1.88 \mathrm{~mm}$

Inner 2nd layer Carbon steel tube filled with NSC with compressive strength $=$ ts $=2.01 \mathrm{~mm}$

$55.3 \mathrm{Mpa}$

Figure 12. Schematic sketch of CFDST cross section with third modification by [1-3] and material properties for specimens with $89 \mathrm{~mm}$ outer diameter of the internal tube.

This subsection of the numerical analysis presented the meshing and elements for Concrete Filled Double skin Steel Tubular column members with 1st sandwich layer filled with UHPFRC and internal carbon steel tube filled with NSC under transverse impact load investigation in accordance to the properties stated by [19]. This is including CFDST elemenet, supports, drop hammer and FE model. The numerical meshing and elements of the fouth modeling analysis part for the proposed modification 3 - CFDST with 1st sandwich layer filled with UHPFRC and internal carbon steel tube filled with NSC under transverse impact load investigation was as follows:

- The mesh for both the outer first layer stainless steel tube and the inner second layer carbon steel tube were simulated using S4R 4-node shell elements.

- The mesh for both UHPFRC and NSC were simulated using C3D8R 8-node solid element.

With reference to [19], the mesh for supports was built using R3D4 4-node quadrilateral rigid element. Again, as recommended by [19], the mesh for drop hammer was built using R3D4 4-node quadrilateral rigid element.

\section{Author propositions of novel triple skin CFST under the effect of sudden impact}

The author of this paper proposes two novel triple skin CFST under the effect of sudden impact. Where the first design proposition is CFTST with 1st sandwich layer filled with UHPFRC and 2nd sandwich layer filled with NSC and the second proposition is CFTST with 1st sandwich layer filled with UHPFRC, 2nd sandwich layer filled with NSC and 3rd skin internal tube filled with NSC.

\subsection{First proposition of novel triple skin CFST under the effect of sudden impact - CFTST with 1st sandwich layer filled with UHPFRC and 2nd sandwich layer filled with NSC}

The fifth stage of the numerical analysis involves the first novel design proposition of triple skin CFST. Moreover, this stage introduces the first Concrete Filled Triple skinned Steel Tube (CFTST) subjected to sudden impact. Furthermore, this will be carried out by inducing an addition third internal carbon steel tube to the tested specimens by [19]. In addition, this design modification has two concrete fill sandwich layers. The first concrete fill sandwich layer lays between the outer stainless-steel tube and the inner second layer carbon steel tube. Besides, the first concrete fill sandwich layer will be filled with Ultra 
High-Performance Fiber Reinforced Polymer (UHPFRC). Furthermore, the second concrete fill sandwich layer lays between the inner second layer carbon steel tube and the inner third layer carbon steel tube. Moreover, the second concrete fill sandwich layer will be filled with Normal Strength Concrete (NSC). Afterwards, the structural behavior will be assisted under transverse impact loading. Moreover, the results obtained will be compared with the experimental results achieved by [19] to determine the percentage of increase in the impact resistivity of the 4th proposed design. As shown in Table 8, the fifth stage of this study consists of eighteen numerical models (simulation numbers 73 to 90 ). Again, three main variables will be evaluated (diameter of internal carbon steel tube, magnitude of axial load and drop height). In addition, Table 8 presents a detailed list of geometrical properties, cross sectional dimensions and impact loading conditions for the 4th proposed modification on the CFDST specimens carried out by [19]. Besides, the list which presented in Table 8 includes details of the simulation numbers, specimens tag numbers, type of modification for this stage, diameter and thickness of the steel tubes, length of the specimens, magnitude of axial load, drop heights, impact mass, impact energy and geometry and size of indenter.

Table 8. List of geometrical properties, cross sectional dimensions and impact loading conditions for CFTST specimens with first proposition of novel triple skin CFST.

\begin{tabular}{|c|c|c|c|c|c|c|c|c|c|c|c|c|c|}
\hline \multirow{2}{*}{ 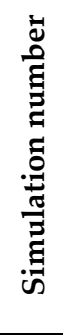 } & \multirow{2}{*}{$\begin{array}{c}\text { Speci- } \\
\text { men } \\
\text { Tag } \\
\text { number }\end{array}$} & \multicolumn{2}{|c|}{$\begin{array}{c}\text { Outer } \\
\text { 1st layer } \\
\text { Stainless } \\
\text { Steel tube }\end{array}$} & \multicolumn{2}{|c|}{$\begin{array}{c}\text { Inner } \\
\text { 2nd layer } \\
\text { Carbon Steel } \\
\text { tube }\end{array}$} & \multicolumn{2}{|c|}{$\begin{array}{l}\text { Inner } \\
\text { 3rd layer } \\
\text { Carbon } \\
\text { Steel tube }\end{array}$} & \multirow[t]{2}{*}{ ⿷્ష్త్ } & \multirow{2}{*}{ 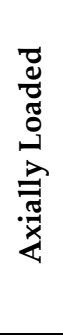 } & \multirow{2}{*}{ 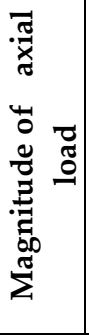 } & \multirow[t]{2}{*}{ छ్ } & \multirow{2}{*}{ 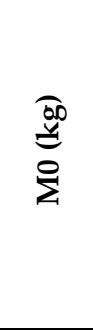 } & \multirow[t]{2}{*}{ 氕 } \\
\hline & & 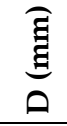 & 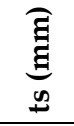 & $\begin{array}{l}\widehat{\Xi} \\
\text { g్ } \\
0\end{array}$ & $\underset{\infty}{\text { छ్ }}$ & 急 & 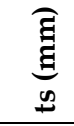 & & & & & & \\
\hline 73 & $\begin{array}{c}\text { L-3-0-a- } \\
\text { M4 }\end{array}$ & 114 & 1.88 & 81.32 & 2.52 & 48 & 2.52 & \multirow{10}{*}{ 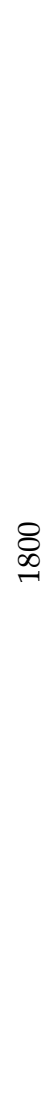 } & No & 0 & 3 & 203.7 & 6 \\
\hline 74 & $\begin{array}{c}\text { L-3-0-b- } \\
\text { M4 }\end{array}$ & 114 & 1.88 & 81.32 & 2.52 & 48 & 2.52 & & No & 0 & 3 & 203.7 & 6 \\
\hline 75 & $\begin{array}{c}\text { L-5-0.5- } \\
\text { a-M4 }\end{array}$ & 114 & 1.88 & 81.32 & 2.52 & 48 & 2.52 & & Yes & 343 & 5 & 203.7 & 10 \\
\hline 76 & $\begin{array}{c}\text { L-5-0.5- } \\
\text { b-M4 }\end{array}$ & 114 & 1.88 & 81.32 & 2.52 & 48 & 2.52 & & Yes & 343 & 5 & 203.7 & 10 \\
\hline 77 & $\begin{array}{c}\text { L-7-0.3- } \\
\text { a-M4 }\end{array}$ & 114 & 1.88 & 81.32 & 2.52 & 48 & 2.52 & & Yes & 206 & 7 & 203.7 & 14 \\
\hline 78 & $\begin{array}{c}\text { L-7-0.3- } \\
\text { b-M4 }\end{array}$ & 114 & 1.88 & 81.32 & 2.52 & 48 & 2.52 & & Yes & 206 & 7 & 203.7 & 14 \\
\hline 79 & $\begin{array}{c}\text { M-3-0.5- } \\
\text { a-M4 }\end{array}$ & 114 & 1.88 & 76 & 2.01 & 38 & 2.01 & & Yes & 317 & 3 & 203.7 & 6 \\
\hline 80 & $\begin{array}{c}\text { M-3-0.5- } \\
\text { b-M4 }\end{array}$ & 114 & 1.88 & 76 & 2.01 & 38 & 2.01 & & Yes & 317 & 3 & 203.7 & 6 \\
\hline 81 & $\begin{array}{c}\text { M-5-0.3- } \\
\text { a-M4 }\end{array}$ & 114 & 1.88 & 76 & 2.01 & 38 & 2.01 & & Yes & 190 & 5 & 203.7 & 10 \\
\hline 82 & $\begin{array}{c}\text { M-5-0.3- } \\
\text { b-M4 }\end{array}$ & 114 & 1.88 & 76 & 2.01 & 38 & 2.01 & & Yes & 190 & 5 & 203.7 & 10 \\
\hline
\end{tabular}




\begin{tabular}{|c|c|c|c|c|c|c|c|c|c|c|c|c|}
\hline 83 & $\begin{array}{c}\text { M-7-0-a- } \\
\text { M4 }\end{array}$ & 114 & 1.88 & 76 & 2.01 & 38 & 2.01 & No & 0 & 7 & 203.7 & 14 \\
\hline 84 & $\begin{array}{c}\text { M-7-0-b- } \\
\text { M4 }\end{array}$ & 114 & 1.88 & 76 & 2.01 & 38 & 2.01 & No & 0 & 7 & 203.7 & 14 \\
\hline 85 & $\begin{array}{c}\text { H-3-0.3- } \\
\text { a-M4 }\end{array}$ & 114 & 1.88 & 89 & 2.01 & 64 & 2.01 & Yes & 142 & 3 & 203.7 & 6 \\
\hline 86 & $\begin{array}{c}\text { H-3-0.3- } \\
\text { b-M4 }\end{array}$ & 114 & 1.88 & 89 & 2.01 & 64 & 2.01 & Yes & 142 & 3 & 203.7 & 6 \\
\hline 87 & $\begin{array}{c}\text { H-5-0-a- } \\
\text { M4 }\end{array}$ & 114 & 1.88 & 89 & 2.01 & 64 & 2.01 & No & 0 & 5 & 203.7 & 10 \\
\hline 88 & $\begin{array}{c}\text { H-5-0-b- } \\
\text { M4 }\end{array}$ & 114 & 1.88 & 89 & 2.01 & 64 & 2.01 & No & 0 & 5 & 203.7 & 10 \\
\hline 89 & $\begin{array}{c}\text { H-7-0.5- } \\
\text { a-M4 }\end{array}$ & 114 & 1.88 & 89 & 2.01 & 64 & 2.01 & Yes & 237 & 7 & 203.7 & 14 \\
\hline 90 & $\begin{array}{c}\text { H-7-0.5- } \\
\text { b-M4 }\end{array}$ & 114 & 1.88 & 89 & 2.01 & 64 & 2.01 & Yes & 237 & 7 & 203.7 & 14 \\
\hline
\end{tabular}

Modification 4 - (1) Adding Triple skin details highlighted in blue, (2) Filling the 1st sandwich layer between the Outer 1st layer Stainless Steel tube and the Inner 2nd layer Carbon Steel tube with UHPFRC, (3) Filling the $2^{\text {nd }}$ sandwich layer between the Inner 2nd layer Carbon Steel tube and the Inner 3rd layer Carbon Steel tube with NSC \& (4) Keep the Inner 3rd layer Carbon Steel tube hollow and unfilled. Impactor/Indenter geometry and size - drop hammer with $30 \mathrm{~mm} \times 80 \mathrm{~mm}$ rectangular bottom surface.

A schematic drawing has been shown in Figure 13 of the CFTST cross section with 4th modification and material properties for specimens with third layer inner steel tube (diameter of $48 \mathrm{~mm}$ ). As can be seen in Figure 13, the model consists of three steel tubes. The first layer outer steel tube is made from stainless steel with an outer diameter of $114 \mathrm{~mm}$ with a tube thickness of $1.88 \mathrm{~mm}$. On the other hand, the second layer inner steel tube represents the additional proposed steel skin and is made from carbon steel with an outer diameter of $81.32 \mathrm{~mm}$ and a thickness of $2.52 \mathrm{~mm}$. Moreover, the third layer inner steel tube is made from carbon steel with an outer diameter of $48 \mathrm{~mm}$ and tube thickness of $2.52 \mathrm{~mm}$. Furthermore, the first concrete fill sandwich layer between the outer stainlesssteel tube and the inner second layer carbon steel tube will be filled with Ultra High-Performance Fiber Reinforced Polymer (UHPFRC). Besides the compressive strength of the UHPFRC will be 152MPa with reference to the material properties used by [15-16]. Contrariwise, the second concrete fill sandwich layer between the inner second layer carbon steel tube and the inner third layer carbon steel tube will be filled with Normal Strength Concrete (NSC) - compressive strength of 55.3MPa. Furthermore, the inner third layer carbon steel tube with be unfilled/hollow. Moreover, all the numerically analyzed specimens has a standard length of $1800 \mathrm{~mm}$.

This proposed modification design in figure 13 will represent simulation numbers 73 to 78 with variations in magnitude of axial load, drop height and impact energy. For example, simulations number 73 and 74 will not be axially load, the drop height will be set at $3 \mathrm{~m}$ and the impact energy will be $6 \mathrm{~kJ}$. While simulation numbers 75 and 76 will be axially loaded with a magnitude of $343 \mathrm{kN}$, the drop height will be set at $5 \mathrm{~m}$ and the impact energy will be around 10kJ. Furthermore, simulation numbers 77 and 78 will be axially loaded with a magnitude of $206 \mathrm{kN}$, the drop height will be set at $7 \mathrm{~m}$ and the impact energy will be $14 \mathrm{~kJ}$. Moreover, the drop mass will have the same magnitude for all the simulations with a value of $203.7 \mathrm{Kg}$. Finally, the geometry of the bottom surface of the drop hammer indenter is rectangular and with a parameter of $30 \mathrm{~mm}$ by $80 \mathrm{~mm}$. 


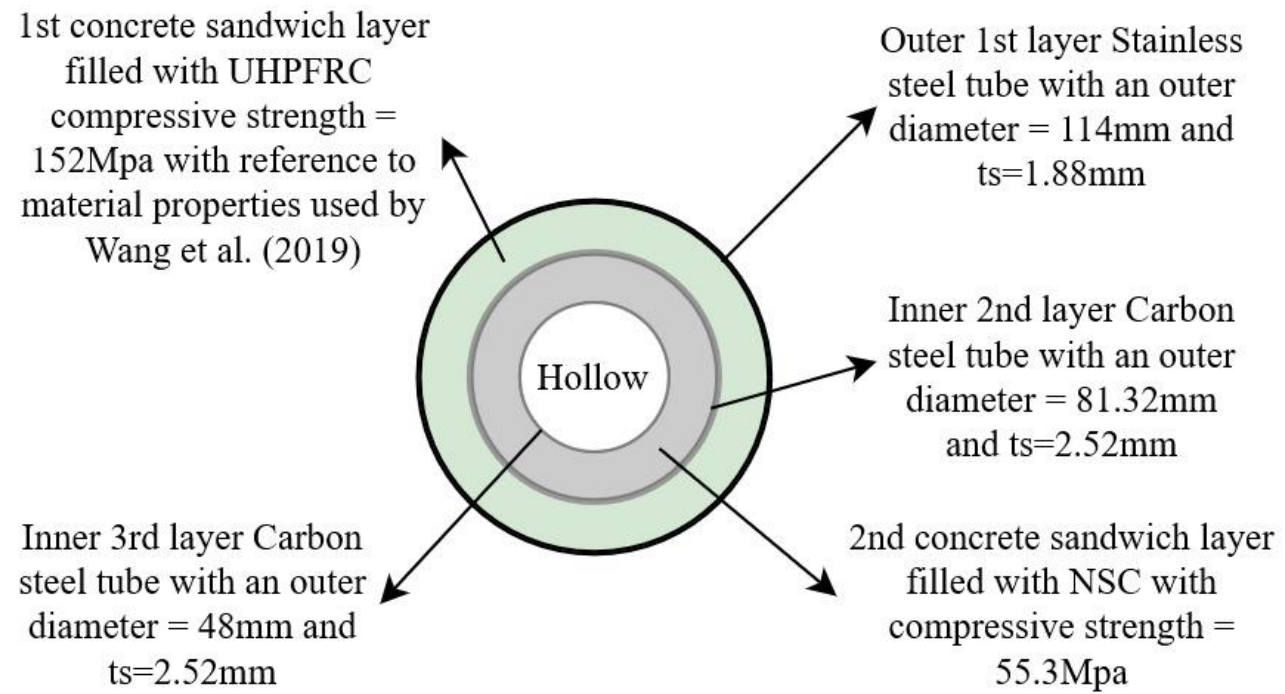

Figure 13. Schematic sketch of the first proposition of novel triple skin CFST and material properties for specimens with an addition 2 nd internal tube $(\mathrm{D}=81.32 \mathrm{~mm})$.

A schematic drawing has been shown in Figure 14 of the CFTST cross section with 4th modification and material properties for specimens with third layer inner steel tube (diameter of $48 \mathrm{~mm}$ ). As can be seen in Figure 14, the model consists of three steel tubes. The first layer outer steel tube is made from stainless steel with an outer diameter of $114 \mathrm{~mm}$ with a tube thickness of $1.88 \mathrm{~mm}$. Moreover, the second layer inner steel tube is made from carbon steel with an outer diameter of $76 \mathrm{~mm}$ and a thickness of $2.01 \mathrm{~mm}$. On the other hand, the third layer inner steel tube represents the additional proposed steel skin and is made from carbon steel with an outer diameter of $38 \mathrm{~mm}$ and tube thickness of $2.01 \mathrm{~mm}$. Furthermore, the first concrete fill sandwich layer between the outer stainlesssteel tube and the inner second layer carbon steel tube will be filled with Ultra High-Performance Fiber Reinforced Polymer (UHPFRC). Besides the compressive strength of the UHPFRC will be 152MPa with reference to the material properties used by [15-16]. Contrariwise, the second concrete fill sandwich layer between the inner second layer carbon steel tube and the inner third layer carbon steel tube will be filled with Normal Strength Concrete (NSC) - compressive strength of 55.3MPa. Furthermore, the inner third layer carbon steel tube with be unfilled/hollow. Moreover, all the numerically analyzed specimens has a standard length of $1800 \mathrm{~mm}$.

This design modification in figure 14 will represent simulation numbers 79 to 84 with variations in magnitude of axial load, drop height and impact energy. For example, simulations number 79 and 80 will be axially load with a magnitude of $317 \mathrm{kN}$, the drop height will be set at $3 \mathrm{~m}$ and the impact energy will be $6 \mathrm{~kJ}$. While simulation numbers 81 and 82 will be axially loaded with a magnitude of $190 \mathrm{kN}$, the drop height will be set at $5 \mathrm{~m}$ and the impact energy will be around 10kJ. Furthermore, simulation numbers 83 and 84 will not be axially loaded, the drop height will be set at $7 \mathrm{~m}$ and the impact energy will be $14 \mathrm{~kJ}$. Moreover, the drop mass will have the same magnitude for all the simulations with a value of $203.7 \mathrm{Kg}$. Finally, the geometry of the bottom surface of the drop hammer indenter is rectangular and with a parameter of $30 \mathrm{~mm}$ by $80 \mathrm{~mm}$. 


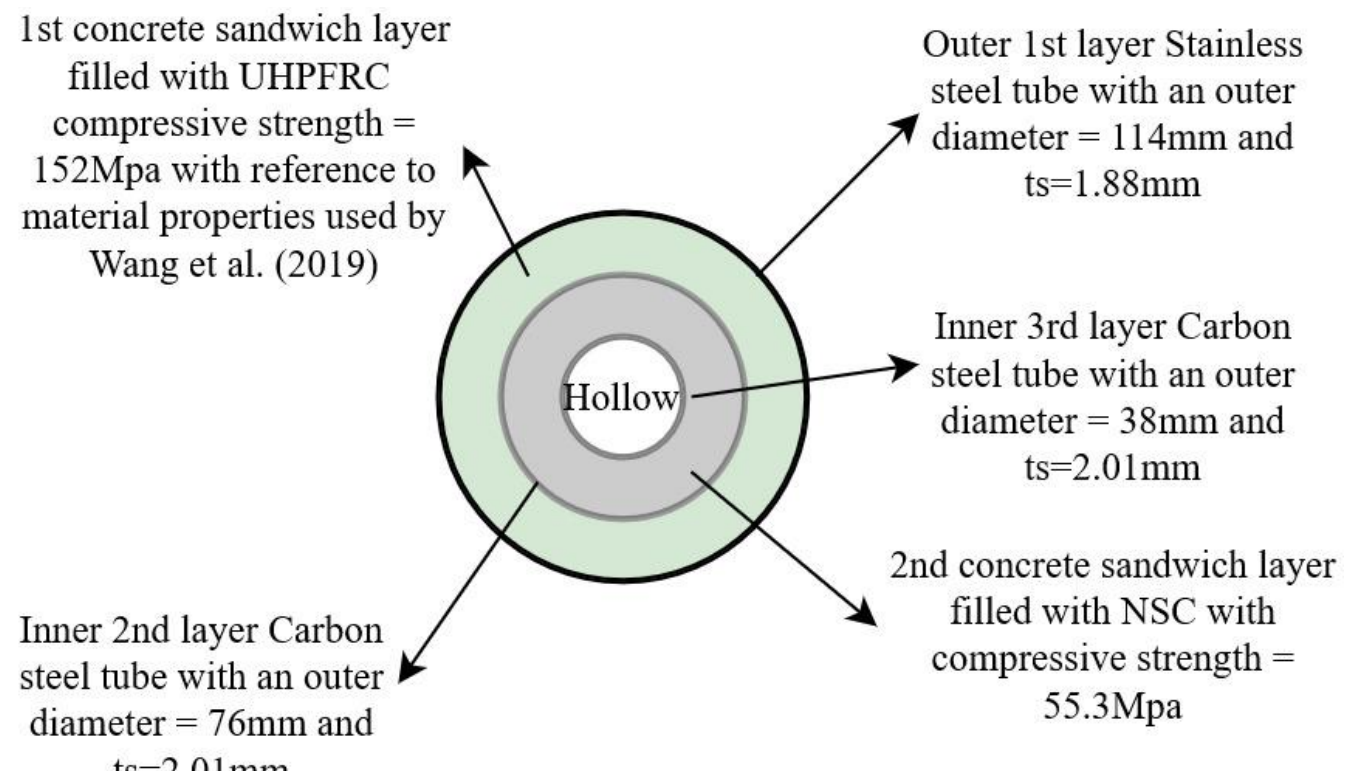

Figure 14. Schematic sketch of the first proposition of novel triple skin CFST and material properties for specimens with an addition 3rd internal tube $(D=38 \mathrm{~mm})$.

A schematic drawing has been shown in Figure 15 of the CFTST cross section with 4th modification and material properties for specimens with third layer inner steel tube (diameter of $64 \mathrm{~mm}$ ). As can be seen in Figure 15, the model consists of three steel tubes. The first layer outer steel tube is made from stainless steel with an outer diameter of $114 \mathrm{~mm}$ with a tube thickness of $1.88 \mathrm{~mm}$. Moreover, the second layer inner steel tube is made from carbon steel with an outer diameter of $89 \mathrm{~mm}$ and a thickness of $2.01 \mathrm{~mm}$. On the other hand, the third layer inner steel tube represents the additional proposed steel skin and is made from carbon steel with an outer diameter of $64 \mathrm{~mm}$ and tube thickness of $2.01 \mathrm{~mm}$. Furthermore, the first concrete fill sandwich layer between the outer stainlesssteel tube and the inner second layer carbon steel tube will be filled with Ultra High-Performance Fiber Reinforced Polymer (UHPFRC). Besides the compressive strength of the UHPFRC will be 152MPa with reference to the material properties used by [15-16]. Inversely, the second concrete fill sandwich layer between the inner second layer carbon steel tube and the inner third layer carbon steel tube will be filled with Normal Strength Concrete (NSC) - compressive strength of 55.3MPa. Furthermore, the inner third layer carbon steel tube with be unfilled/hollow. Moreover, all the numerically analyzed specimens has a standard length of $1800 \mathrm{~mm}$.

This design modification in figure 15 will represent simulation numbers 85 to 90 with variations in magnitude of axial load, drop height and impact energy. For example, simulations number 85 and 86 will be axially load with a magnitude of $142 \mathrm{kN}$, the drop height will be set at $3 \mathrm{~m}$ and the impact energy will be $6 \mathrm{~kJ}$. While simulation numbers 87 and 88 will not be axially loaded, the drop height will be set at $5 \mathrm{~m}$ and the impact energy will be around 10kJ. Furthermore, simulation numbers 89 and 90 will be axially loaded with a magnitude of $237 \mathrm{kN}$, the drop height will be set at $7 \mathrm{~m}$ and the impact energy will be $14 \mathrm{~kJ}$. Moreover, the drop mass will have the same magnitude for all the simulations with a value of $203.7 \mathrm{Kg}$. Finally, the geometry of the bottom surface of the drop hammer indenter is rectangular and with a parameter of $30 \mathrm{~mm}$ by $80 \mathrm{~mm}$. 


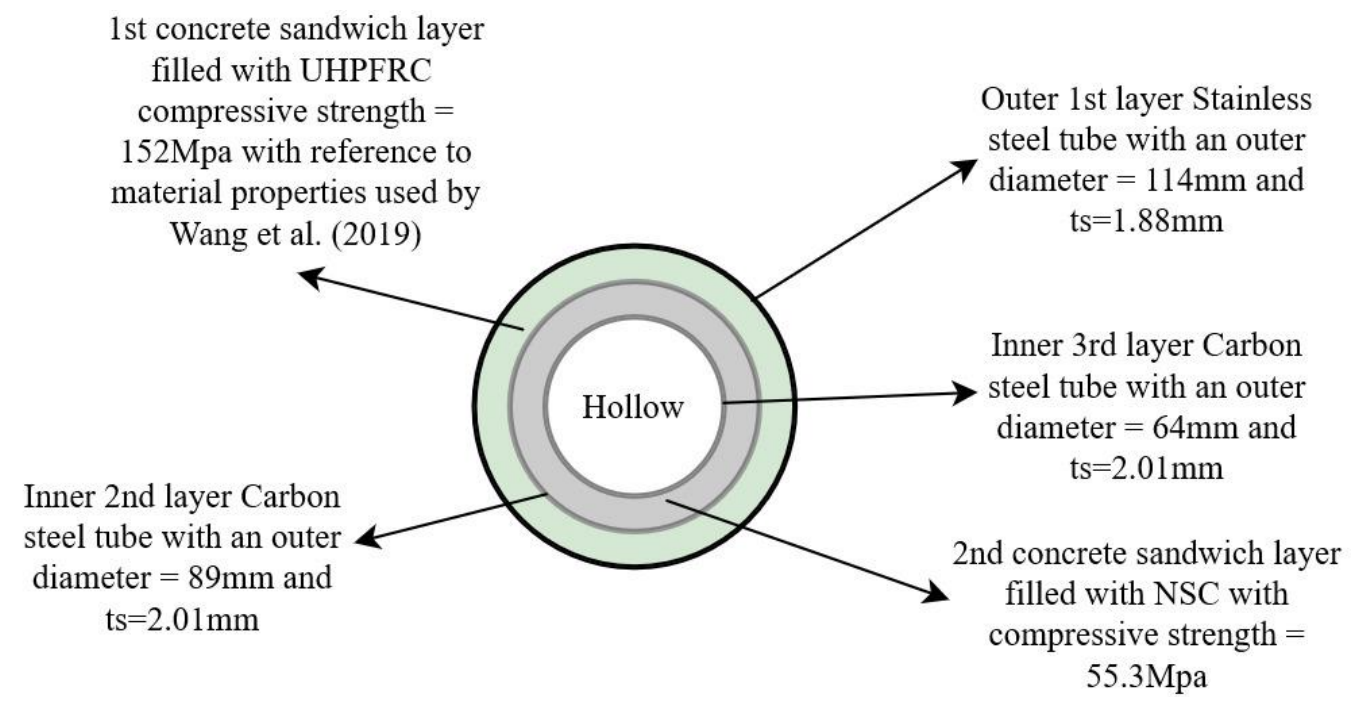

Figure 15. Schematic sketch of the first proposition of novel triple skin CFST and material properties for specimens with an addition 3 rd internal tube $(D=64 \mathrm{~mm})$.

This subsection of the numerical analysis will present the meshing and elements for Concrete Filled Triple skin Steel Tubular column members with 1st sandwich layer filled with UHPFRC and 2nd sandwich layer filled with NSC under transverse impact load investigation in accordance to the properties stated by [19]. Furthermore, this subsection has been divided into four parts (1) CFDST elemenet, (2) supports, (3) drop hammer and (4) FE model. The numerical meshing and elements of the fifth modeling analysis part for the proposed modification 4 - CFTST with 1st sandwich layer filled with UHPFRC and 2nd sandwich layer filled with NSC under transverse impact load investigation will be as follows:

- The mesh for the outer first layer stainless steel tube, the inner second layer carbon steel tube and the inner third layer carbon steel tube will be simulated using S4R 4-node shell elements.

- The mesh for both UHPFRC and NSC sandwich layers will be simulated using C3D8R 8-node solid element.

With reference to [19], the mesh for supports will be built using R3D4 4-node quadrilateral rigid element. Again, as recommended by [19], the mesh for drop hammer was built using R3D4 4-node quadrilateral rigid element.

\subsection{Second proposition of novel triple skin CFST under the effect of sudden impact - CFTST with 1st sandwich layer filled with UHPFRC, 2nd sandwich layer filled with NSC and 3rd skin internal tube filled with NSC}

The fifth stage of the numerical analysis involves the first novel design proposition of triple skin CFST. In addition, this design modification has three concrete fill sandwich layers. The first concrete fill sandwich layer lays between the outer stainless-steel tube and the inner second layer carbon steel tube. Besides, the first concrete fill sandwich layer will be filled with Ultra High-Performance Fiber Reinforced Polymer (UHPFRC). Furthermore, the second concrete fill sandwich layer lays between the inner second layer carbon steel tube and the inner third layer carbon steel tube. Moreover, the second concrete fill sandwich layer will be filled with Normal Strength Concrete (NSC). Moreover, the third concrete fill sandwich layer will be located in the core of the inner third skin carbon steel tube. In addition, the third concrete fill sandwich layer will be filled with Normal Strength Concrete (NSC). Afterwards, the structural behavior will be assisted under transverse impact loading. Moreover, the results obtained will be compared with the experimental results achieved by [19] to determine the percentage of increase in the impact resistivity of the 
5th proposed design. As shown in Table 9, the sixth stage of this study consists of eighteen numerical models (simulation numbers 91 to 108). Again, three main variables will be evaluated (diameter of internal carbon steel tube, magnitude of axial load and drop height). In addition, Table 9 presents a detailed list of geometrical properties, cross sectional dimensions and impact loading conditions for the 5th proposed modification on the CFDST specimens carried out by [19]. Besides, the list which presented in Table 9 includes details of the simulation numbers, specimens tag numbers, type of modification for this stage, diameter and thickness of the steel tubes, length of the specimens, magnitude of axial load, drop heights, impact mass, impact energy and geometry and size of indenter.

Table 9. List of geometrical properties, cross sectional dimensions and impact loading conditions for CFTST specimens with second proposition of novel triple skin CFST.

\begin{tabular}{|c|c|c|c|c|c|c|c|c|c|c|c|c|c|}
\hline \multirow{2}{*}{ 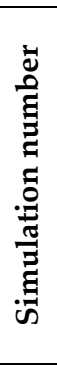 } & \multirow{2}{*}{$\begin{array}{l}\text { Speci- } \\
\text { men } \\
\text { Tag } \\
\text { num- } \\
\text { ber }\end{array}$} & \multicolumn{2}{|c|}{$\begin{array}{c}\text { Outer } \\
\text { 1st layer } \\
\text { Stainless } \\
\text { Steel tube }\end{array}$} & \multicolumn{2}{|c|}{$\begin{array}{c}\text { Inner } \\
\text { 2nd layer } \\
\text { Carbon Steel } \\
\text { tube }\end{array}$} & \multicolumn{2}{|c|}{$\begin{array}{l}\text { Inner } \\
\text { 3rd layer } \\
\text { Carbon } \\
\text { Steel tube }\end{array}$} & \multirow{2}{*}{$\underset{\Xi}{\mathfrak{\Xi}}$} & \multirow{2}{*}{ 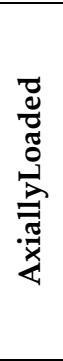 } & \multirow{2}{*}{ 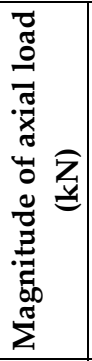 } & \multirow{2}{*}{$\begin{array}{l}\text { छ } \\
\text { II }\end{array}$} & \multirow{2}{*}{ 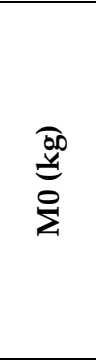 } & \multirow{2}{*}{ 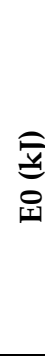 } \\
\hline & & 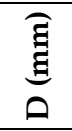 & 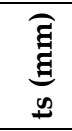 & $\begin{array}{l}\mathfrak{\Xi} \\
\text { ఏ }\end{array}$ & 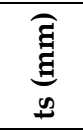 & 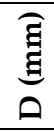 & $\underset{\infty}{\mathfrak{\Xi}}$ & & & & & & \\
\hline 91 & $\begin{array}{l}\text { L-3-0- } \\
\text { a-M5 }\end{array}$ & 114 & 1.88 & 81.32 & 2.52 & 48 & 2.52 & & No & 0 & 3 & 203.7 & 6 \\
\hline 92 & $\begin{array}{l}\text { L-3-0- } \\
\text { b-M5 }\end{array}$ & 114 & 1.88 & 81.32 & 2.52 & 48 & 2.52 & & No & 0 & 3 & 203.7 & 6 \\
\hline 93 & $\begin{array}{c}\text { L-5- } \\
0.5-a- \\
\text { M5 }\end{array}$ & 114 & 1.88 & 81.32 & 2.52 & 48 & 2.52 & & Yes & 343 & 5 & 203.7 & 10 \\
\hline 94 & $\begin{array}{c}\text { L-5- } \\
0.5-b- \\
\text { M5 }\end{array}$ & 114 & 1.88 & 81.32 & 2.52 & 48 & 2.52 & & Yes & 343 & 5 & 203.7 & 10 \\
\hline 95 & $\begin{array}{c}\text { L-7- } \\
0.3-a- \\
\text { M5 }\end{array}$ & 114 & 1.88 & 81.32 & 2.52 & 48 & 2.52 & 5 & Yes & 206 & 7 & 203.7 & 14 \\
\hline 96 & $\begin{array}{c}\text { L-7- } \\
0.3-b- \\
\text { M5 }\end{array}$ & 114 & 1.88 & 81.32 & 2.52 & 48 & 2.52 & & Yes & 206 & 7 & 203.7 & 14 \\
\hline 97 & $\begin{array}{c}\text { M-3- } \\
0.5-a- \\
\text { M5 }\end{array}$ & 114 & 1.88 & 76 & 2.01 & 38 & 2.01 & & Yes & 317 & 3 & 203.7 & 6 \\
\hline 98 & $\begin{array}{c}\text { M-3- } \\
0.5-b- \\
\text { M5 }\end{array}$ & 114 & 1.88 & 76 & 2.01 & 38 & 2.01 & & Yes & 317 & 3 & 203.7 & 6 \\
\hline 99 & $\begin{array}{c}\text { M-5- } \\
0.3-a- \\
\text { M5 }\end{array}$ & 114 & 1.88 & 76 & 2.01 & 38 & 2.01 & & Yes & 190 & 5 & 203.7 & 10 \\
\hline
\end{tabular}




\begin{tabular}{|c|c|c|c|c|c|c|c|c|c|c|c|c|}
\hline 100 & $\begin{array}{c}0.3-b- \\
\text { M5 }\end{array}$ & 114 & 1.88 & 76 & 2.01 & 38 & 2.01 & Yes & 190 & 5 & 203.7 & 10 \\
\hline 101 & $\begin{array}{l}\text { M-7-0- } \\
\text { a-M5 }\end{array}$ & 114 & 1.88 & 76 & 2.01 & 38 & 2.01 & No & 0 & 7 & 203.7 & 14 \\
\hline 102 & $\begin{array}{c}\text { M-7-0- } \\
\text { b-M5 }\end{array}$ & 114 & 1.88 & 76 & 2.01 & 38 & 2.01 & No & 0 & 7 & 203.7 & 14 \\
\hline 103 & $\begin{array}{c}\text { H-3- } \\
0.3-a- \\
\text { M5 }\end{array}$ & 114 & 1.88 & 89 & 2.01 & 64 & 2.01 & Yes & 142 & 3 & 203.7 & 6 \\
\hline 104 & $\begin{array}{c}\text { H-3- } \\
0.3-b- \\
\text { M5 }\end{array}$ & 114 & 1.88 & 89 & 2.01 & 64 & 2.01 & Yes & 142 & 3 & 203.7 & 6 \\
\hline 105 & $\begin{array}{l}\text { H-5-0- } \\
\text { a-M5 }\end{array}$ & 114 & 1.88 & 89 & 2.01 & 64 & 2.01 & No & 0 & 5 & 203.7 & 10 \\
\hline 106 & $\begin{array}{l}\text { H-5-0- } \\
\text { b-M5 }\end{array}$ & 114 & 1.88 & 89 & 2.01 & 64 & 2.01 & No & 0 & 5 & 203.7 & 10 \\
\hline 107 & $\begin{array}{c}\text { H-7- } \\
0.5-a- \\
\text { M5 }\end{array}$ & 114 & 1.88 & 89 & 2.01 & 64 & 2.01 & Yes & 237 & 7 & 203.7 & 14 \\
\hline 108 & $\begin{array}{c}\text { H-7- } \\
0.5-b- \\
\text { M5 }\end{array}$ & 114 & 1.88 & 89 & 2.01 & 64 & 2.01 & Yes & 237 & 7 & 203.7 & 14 \\
\hline
\end{tabular}

Modification 5 - All the modifications as in modification 4 + Filling the Inner 3rd layer Carbon Steel tube with NSC.

Impactor/Indenter geometry and size - drop hammer with $30 \mathrm{~mm} \times 80 \mathrm{~mm}$ rectangular bottom surface.

A schematic drawing has been shown in Figure 16 of the CFTST cross section with 5th modification and material properties for specimens with third layer inner steel tube (diameter of $48 \mathrm{~mm}$ ). As can be seen in Figure 16, the model consists of three steel tubes. The first layer outer steel tube is made from stainless steel with an outer diameter of $114 \mathrm{~mm}$ with a tube thickness of $1.88 \mathrm{~mm}$. On the other hand, the second layer inner steel tube represents the additional proposed steel skin and is made from carbon steel with an outer diameter of $81.32 \mathrm{~mm}$ and a thickness of $2.52 \mathrm{~mm}$. Moreover, the third layer inner steel tube is made from carbon steel with an outer diameter of $48 \mathrm{~mm}$ and tube thickness of $2.52 \mathrm{~mm}$. Furthermore, the first concrete fill sandwich layer between the outer stainlesssteel tube and the inner second layer carbon steel tube will be filled with Ultra High-Performance Fiber Reinforced Polymer (UHPFRC). Besides the compressive strength of the UHPFRC will be 152MPa with reference to the material properties used by [15-16]. Contrariwise, the second concrete fill sandwich layer between the inner second layer carbon steel tube and the inner third layer carbon steel tube will be filled with Normal Strength Concrete (NSC) - compressive strength of 55.3MPa. Also, the inner third layer carbon steel tube will be filled with Normal Strength Concrete (NSC) - compressive strength of 55.3MPa. Moreover, all the numerically analyzed specimens has a standard length of $1800 \mathrm{~mm}$. 
This proposed modification design in figure 16 will represent simulation numbers 91 to 96 with variations in magnitude of axial load, drop height and impact energy. For example, simulations number 91 and 92 will not be axially load, the drop height will be set at $3 \mathrm{~m}$ and the impact energy will be $6 \mathrm{~kJ}$. While simulation numbers 93 and 94 will be axially loaded with a magnitude of $343 \mathrm{kN}$, the drop height will be set at $5 \mathrm{~m}$ and the impact energy will be around 10kJ. Furthermore, simulation numbers 95 and 96 will be axially loaded with a magnitude of $206 \mathrm{kN}$, the drop height will be set at $7 \mathrm{~m}$ and the impact energy will be $14 \mathrm{~kJ}$. Moreover, the drop mass will have the same magnitude for all the simulations with a value of $203.7 \mathrm{Kg}$. Finally, the geometry of the bottom surface of the drop hammer indenter is rectangular and with a parameter of $30 \mathrm{~mm}$ by $80 \mathrm{~mm}$.

1st concrete sandwich layer
filled with UHPFRC
compressive strength $=$
152Mpa with reference to
material properties used by
Wang et al. (2019)

Inner 3rd layer Carbon steel tube filled with NSC with compressive strength $=$ 55.3Mpa

Inner 3rd layer Carbon steel tube with an outer diameter $=48 \mathrm{~mm}$ and ts $=2.52 \mathrm{~mm}$
Outer 1st layer Stainless steel tube with an outer diameter $=114 \mathrm{~mm}$ and ts $=1.88 \mathrm{~mm}$

Inner 2nd layer Carbon steel tube with an outer diameter $=81.32 \mathrm{~mm}$ and $\mathrm{ts}=2.52 \mathrm{~mm}$

2nd concrete sandwich layer filled with NSC with compressive strength $=$ 55.3Mpa

Figure 16. Schematic sketch of the second proposition of novel triple skin CFST and material properties for specimens with an addition 2 nd internal tube $(\mathrm{D}=81.32 \mathrm{~mm})$.

A schematic drawing has been shown in Figure 17 of the CFTST cross section with 5 th modification and material properties for specimens with third layer inner steel tube (diameter of 38mm). As can be seen in Figure 17, the model consists of three steel tubes. The first layer outer steel tube is made from stainless steel with an outer diameter of $114 \mathrm{~mm}$ with a tube thickness of $1.88 \mathrm{~mm}$. Moreover, the second layer inner steel tube is made from carbon steel with an outer diameter of $76 \mathrm{~mm}$ and a thickness of $2.01 \mathrm{~mm}$. On the other hand, the third layer inner steel tube represents the additional proposed steel skin and is made from carbon steel with an outer diameter of $38 \mathrm{~mm}$ and tube thickness of $2.01 \mathrm{~mm}$. Furthermore, the first concrete fill sandwich layer between the outer stainlesssteel tube and the inner second layer carbon steel tube will be filled with Ultra High-Performance Fiber Reinforced Polymer (UHPFRC). Besides the compressive strength of the UHPFRC will be 152MPa with reference to the material properties used by [15-16]. Contrariwise, the second concrete fill sandwich layer between the inner second layer carbon steel tube and the inner third layer carbon steel tube will be filled with Normal Strength Concrete (NSC) - compressive strength of 55.3MPa. Also, the inner third layer carbon steel tube will be filled with Normal Strength Concrete (NSC) - compressive strength of 55.3MPa. Moreover, all the numerically analyzed specimens has a standard length of $1800 \mathrm{~mm}$.

This design modification in figure 17 will represent simulation numbers 97 to 102 with variations in magnitude of axial load, drop height and impact energy. For example, simulations number 97 and 98 will be axially load with a magnitude of $317 \mathrm{kN}$, the drop 
height will be set at $3 \mathrm{~m}$ and the impact energy will be $6 \mathrm{~kJ}$. While simulation numbers 99 and 100 will be axially loaded with a magnitude of $190 \mathrm{kN}$, the drop height will be set at $5 \mathrm{~m}$ and the impact energy will be around 10kJ. Furthermore, simulation numbers 101 and 102 will not be axially loaded, the drop height will be set at $7 \mathrm{~m}$ and the impact energy will be $14 \mathrm{~kJ}$. Moreover, the drop mass will have the same magnitude for all the simulations with a value of $203.7 \mathrm{Kg}$. Finally, the geometry of the bottom surface of the drop hammer indenter is rectangular and with a parameter of $30 \mathrm{~mm}$ by $80 \mathrm{~mm}$.

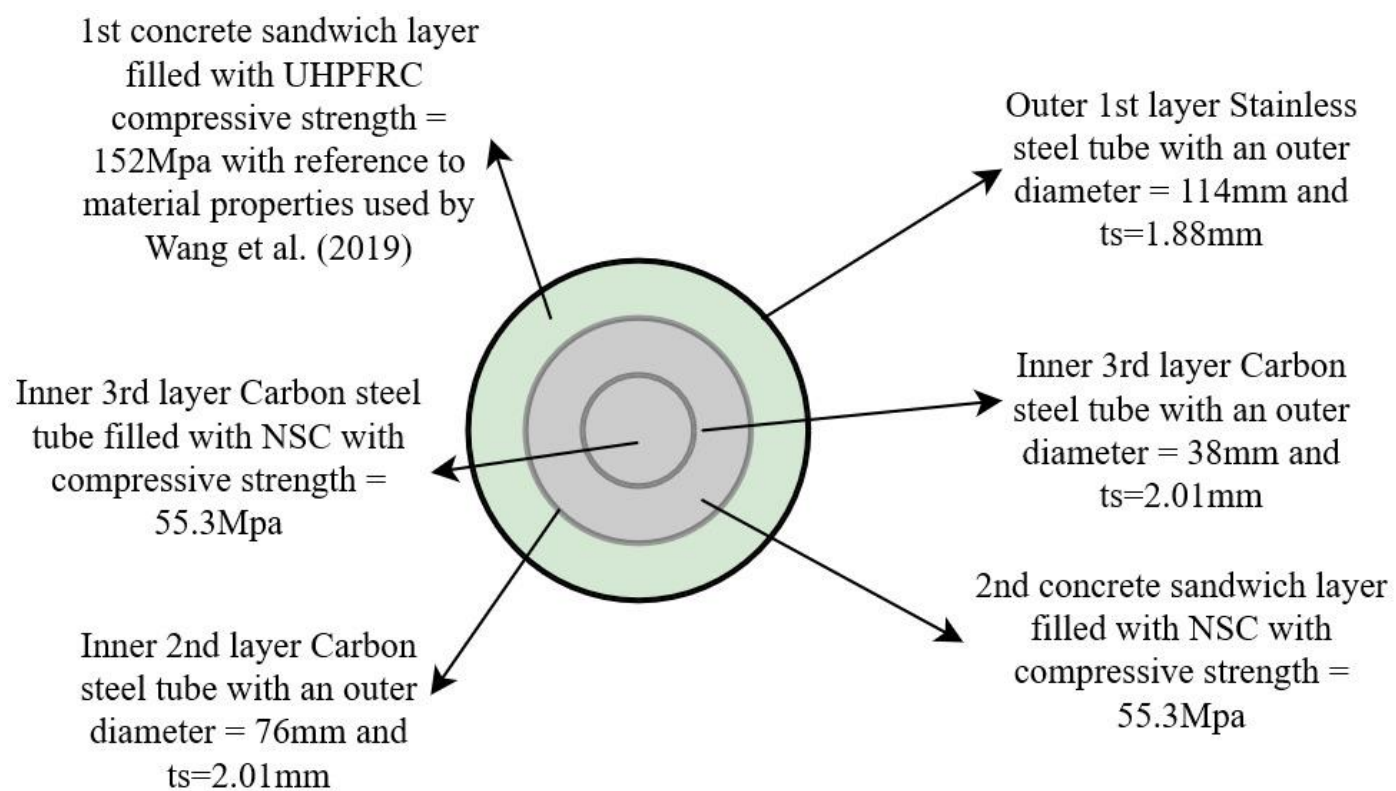

Figure 17. Schematic sketch of the second proposition of novel triple skin CFST and material properties for specimens with an addition 3rd internal tube $(D=38 \mathrm{~mm})$.

A schematic drawing has been shown in Figure 18 of the CFTST cross section with 5th modification and material properties for specimens with third layer inner steel tube (diameter of $64 \mathrm{~mm}$ ). As can be seen in Figure 18, the model consists of three steel tubes. The first layer outer steel tube is made from stainless steel with an outer diameter of $114 \mathrm{~mm}$ with a tube thickness of $1.88 \mathrm{~mm}$. Moreover, the second layer inner steel tube is made from carbon steel with an outer diameter of $89 \mathrm{~mm}$ and a thickness of $2.01 \mathrm{~mm}$. On the other hand, the third layer inner steel tube represents the additional proposed steel skin and is made from carbon steel with an outer diameter of $64 \mathrm{~mm}$ and tube thickness of $2.01 \mathrm{~mm}$. Furthermore, the first concrete fill sandwich layer between the outer stainlesssteel tube and the inner second layer carbon steel tube will be filled with Ultra High-Performance Fiber Reinforced Polymer (UHPFRC). Besides the compressive strength of the UHPFRC will be 152MPa with reference to the material properties used by [15-16]. Inversely, the second concrete fill sandwich layer between the inner second layer carbon steel tube and the inner third layer carbon steel tube will be filled with Normal Strength Concrete (NSC) - compressive strength of 55.3MPa. Also, the inner third layer carbon steel tube will be filled with Normal Strength Concrete (NSC) - compressive strength of 55.3MPa. Moreover, all the numerically analyzed specimens has a standard length of $1800 \mathrm{~mm}$.

This design modification in figure 18 will represent simulation numbers 103 to 108 with variations in magnitude of axial load, drop height and impact energy. For example, simulations number 103 and 104 will be axially load with a magnitude of $142 \mathrm{kN}$, the drop height will be set at $3 \mathrm{~m}$ and the impact energy will be $6 \mathrm{~kJ}$. While simulation numbers 105 and 106 will not be axially loaded, the drop height will be set at $5 \mathrm{~m}$ and the impact energy will be around 10kJ. Furthermore, simulation numbers 107 and 108 will be axially loaded 
with a magnitude of $237 \mathrm{kN}$, the drop height will be set at $7 \mathrm{~m}$ and the impact energy will be $14 \mathrm{~kJ}$. Moreover, the drop mass will have the same magnitude for all the simulations with a value of $203.7 \mathrm{Kg}$. Finally, the geometry of the bottom surface of the drop hammer indenter is rectangular and with a parameter of $30 \mathrm{~mm}$ by $80 \mathrm{~mm}$.

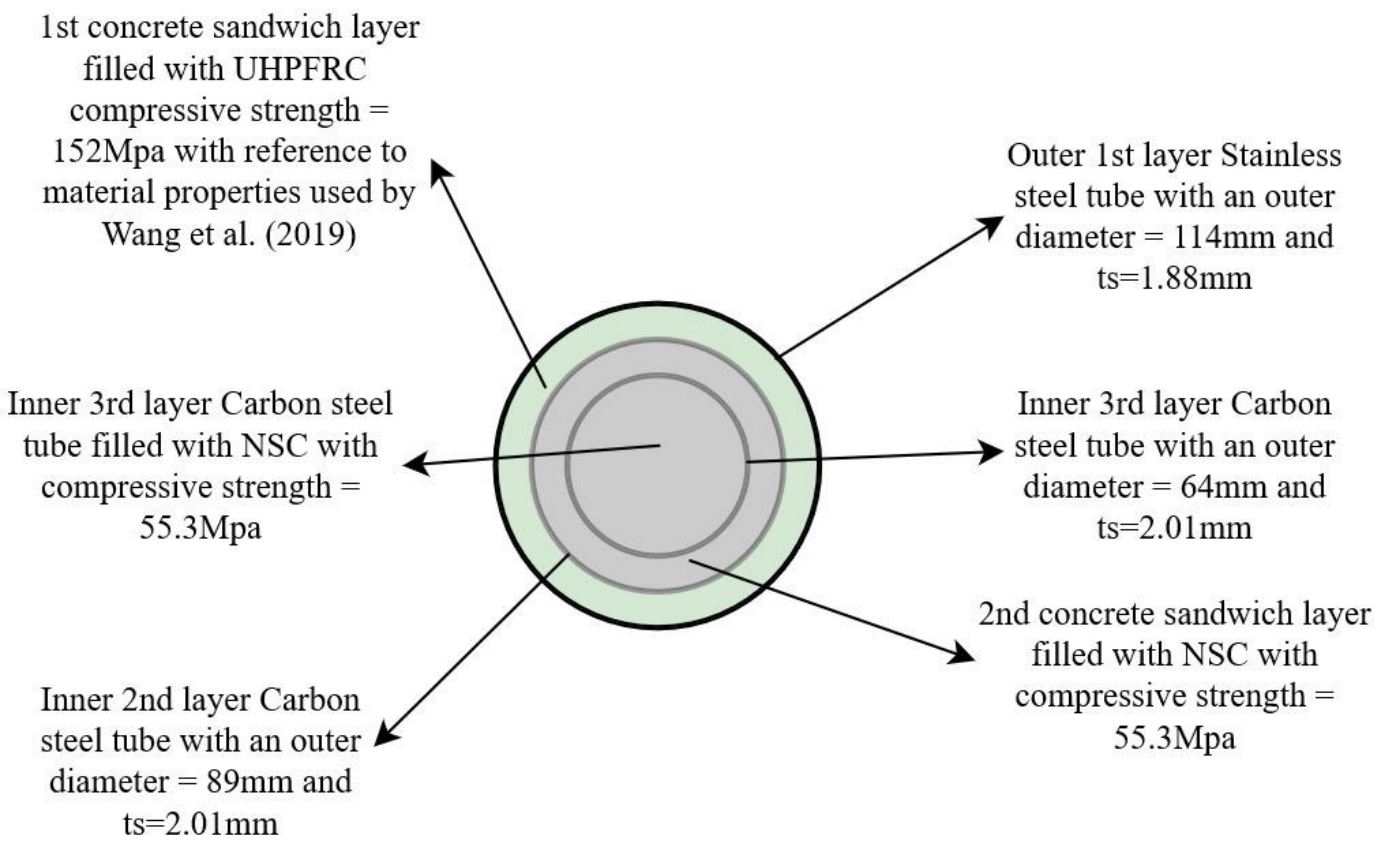

Figure 18. Schematic sketch of the second proposition of novel triple skin CFST and material properties for specimens with an addition 3rd internal tube $(D=64 \mathrm{~mm})$.

This subsection of the numerical analysis will present the meshing and elements for Concrete Filled Triple skin Steel Tubular column members with 1st sandwich layer filled with UHPFRC, 2nd sandwich layer filled with NSC and 3rd skin internal tube filled with NSC under transverse impact load investigation in accordance to the properties stated by [19]. Furthermore, this subsection has been divided into four parts (1) CFDST elemenet, (2) supports, (3) drop hammer and (4) FE model. The numerical meshing and elements of the sixth modeling analysis part for the proposed modification 5 - CFTST with 1st sandwich layer filled with UHPFRC, 2nd sandwich layer filled with NSC and 3rd skin internal tube filled with NSC under transverse impact load investigation will be as follows:

- The mesh for the outer first layer stainless steel tube, the inner second layer carbon steel tube and the inner third layer carbon steel tube will be simulated using S4R 4-node shell elements.

- The mesh for both UHPFRC and NSC sandwich and core layers will be simulated using C3D8R 8-node solid element.

With reference to [19], the mesh for supports will be built using R3D4 4-node quadrilateral rigid element. Again, as recommended by [19], the mesh for drop hammer was built using R3D4 4-node quadrilateral rigid element. Moreover, figure 19 presents the novel triple skin CFST, where (a) is the Model and (b) is elements and mesh. Finally, figure 20 illustrates the proposed triple skin CFST numerical model under the effect of sudden impact. Where RP-1 demonstartes the drop hammer which initiates the sudden impact. 


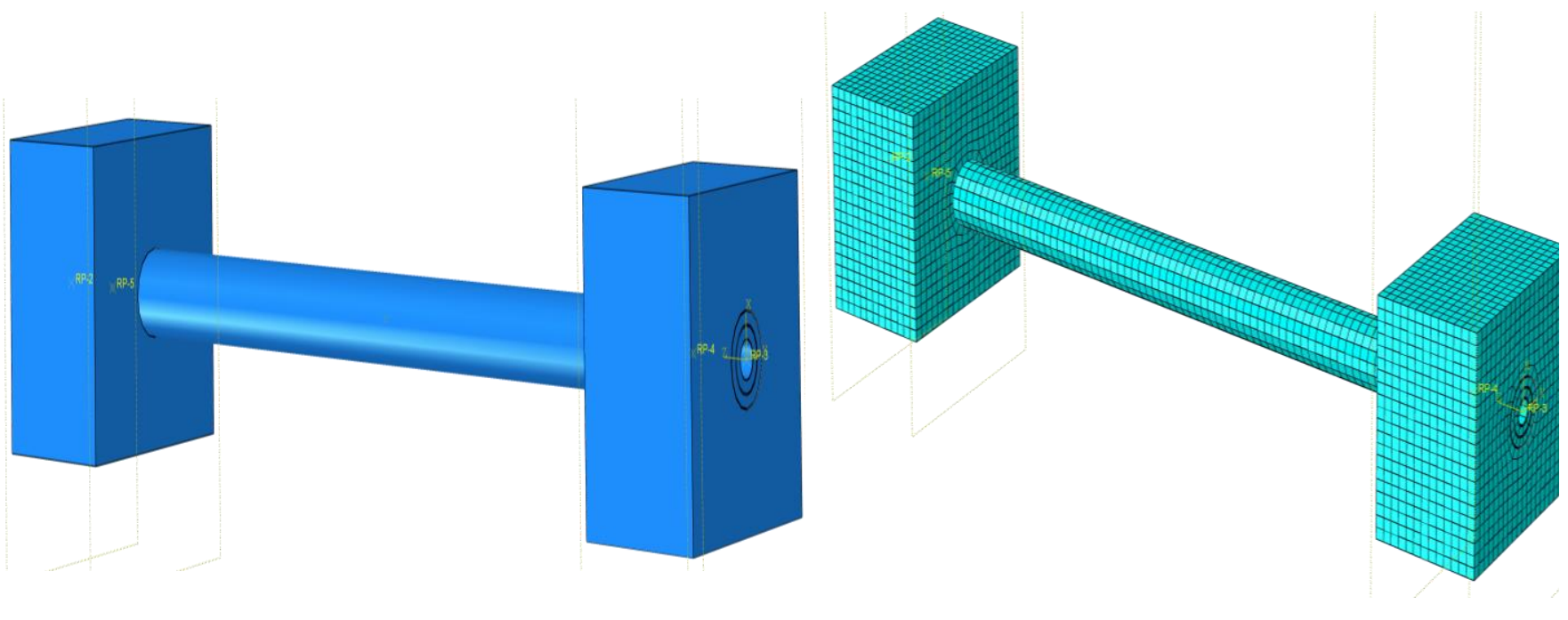

(a)

(b)

Figure 19. Novel Triple Skin Concrete Filled Steel Tubes (TSCFST), where (a) Proposed Model; (b) Elements and meshing.

Figure 20. Novel triple skin CFST numerical model under the effect of sudden impact.

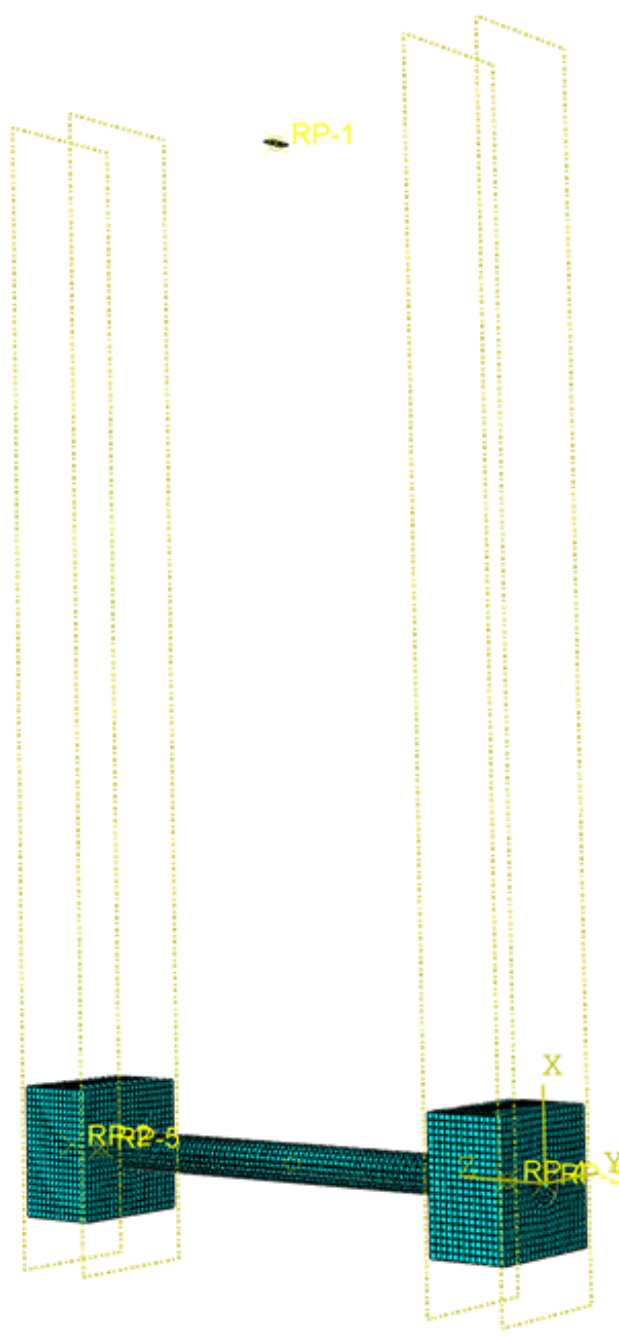




\section{Conclusions}

This paper is a continuation of the researches which were carried out by [1-3]. Consequently, this research proposes analytical analysis of two novel triple skin Concrete Filled Steel Tube (CFST) designs under the effect of sudden impact. It is strongly believed that both the first and the second propositions of novel triple skin CFST will enhance the global impact resistivity of the structural member when comparing with the experimental and numerical double skin CFST models by [1-3] and [19]. Accordingly, the below has been concluded:

- The first proposition of novel triple skin CFST will increase the impact resistivity of the structural member by 25 to $32 \%$.

- The second proposition of novel triple skin CFST will boost the efficiency of the structural member under the event of sudden impact by 28 to $36 \%$.

- Both the first and second triple skin CFST propositions will reduce the residual and maximum displacements by up to $15 \%$ when compared with double skin CFST members.

- The diameter of the triple internal carbon steel tube has a direct relationship with residual displacements after sudden impact. For instance, the higher the diameter results in higher maximum and residual displacements.

- By filling the third triple skin tube with Normal Strength Concrete (NSC), the displacements after impact reduces by up to $12 \%$.

In accordance to the above observations, the author of this paper proposes further numerical investigations on the impact behavior of triple skin stainless steel tubular columns filled with UHPFRC and externally reinforced with Glass Fiber Reinforced Polymer (GFRP).

Conflicts of Interest: “The author declares no conflict of interest."

\section{References}

[1] Abdel Rahim, K. A. N. (2021) Literature Review: Concrete Filled Steel Tubes Under Transverse Impact Loading, Current Trends in Civil \& Structural Engineering 7(3).

[2] Abdel Rahim, K. A. N. (2021) Numerical Modelling of the Behavior of Steel-Concrete Composite Columns of Different Types of Circular Cross Section Subject to Lateral Impact, Civil Engineering Research Journal 11(5).

[3] Abdel Rahim, K. A. N. (2021) Circular double skin stainless steel tubular column filled with UHPFRC subjected to impact load, Global Journal of Civil Engineering, Vol. 02 (2021) pp 1-11.

[4] Alam, M, I.; Fawzia, S.; Zhao, X, L.; Remennikov, A.; M, Bambach.; M, R.; Elchalakani, M. (2017) Performance and dynamic behaviour of FRP strengthened CFST members subjected to lateral impact, Engineering Structures 147: pp 160-176.

[5] Bambach, M, R.; (2011) Design of hollow and concrete filled steel and stainless steel tubular columns for transverse impact loads. ThinWalled Structures 49 (10): pp 1251-1260.

[6] Abaqus (2007) ABAQUS Standard User's Manual, Version 6.7. Providence, RI, Dassault Systèmes Corp, USA.

[7] Han LH, Yao G, Tao Z (2007) Performance of concrete-filled thin-walled steel tubes under pure torsion. Thin Wall Structures 45(1): 24-36.

[8] Hibbitt, Karlsson, Sorensen Inc (2010) ABAQUS Standard User's manual. Version 6.10. RI, USA.

[9] Hou CC, Han LH (2018) Life-cycle performance of deteriorated concrete-filled steel tubular (CFST) structures subject to lateral impact. Thin-Walled Structures 132: 362-374.

[10] Karlsson Sorensen Inc. Hibbitt. (2005), ABAQUS/Explicit User's Manual. New York: Rhode Island; [Version 6.5.1].

[11] Liu FQ, Gardner L, Yang H (2014) Post-fire behaviour of reinforced concrete stub columns confined by circular steel tubes. Journal of Constructional Steel Research 102: 82-103.

[12] Othman H, Marzouk H (2018) Applicability of damage plasticity constitutive model for ultra-high performance fibre-reinforced concrete under impact loads. International Journal of Impact Engineering 114: 20-31.

[13] Tao Z, Wang Z B, Yu Q, 2013, Finite element modelling of concrete-filled steel stub columns under axial compression, Journal of Constructional Steel Research 89: pp 121-131.

[14] Wang R, Han LH, Hou CC (2013) Behavior of concrete filled steel tubular (CFST) members under lateral impact: Experiment and FEA model. Journal of Constructional Steel Research 80: 188-201.

[15] Wang W, Wu C, Li J, Liu Z, Lv Y (2019) Behavior of ultra-high-performance fiber-reinforced concrete (UHPFRC) filled steel tubular members under lateral impact loading. International Journal of Impact Engineering 132: 103314. 
[16] Wang W, Wu C, Liu Z (2019) Compressive behavior of hybrid doubleskin tubular columns with ultra-high-performance fiberreinforced concrete (UHPFRC). Engineering Structures 180: 419-441.

[17] Yang YF, Zhang ZC, Fu F (2015) Experimental and numerical study on square RACFST members under lateral impact loading. Journal of Constructional Steel Research 111: 43-56.

[18] Yousuf M, Uy B, Tao Z, Remennikov A, Liew JYR (2013) Transverse impact resistance of hollow and concrete filled stainless steel columns. Journal of Constructional Steel Research 82: 177-189.

[19] Zhao, H.; Wang, R.; Hou, C.; Lam, D. (2019) Performance of circular CFDST members with external stainless-steel tube under transverse impact loading, Thin-Walled Structures 145: 106380. 